\title{
norden
}

Best Available Techniques (BAT) in solid biomass fuel processing, handling, storage and production of pellets from biomass

(n) की 12 t

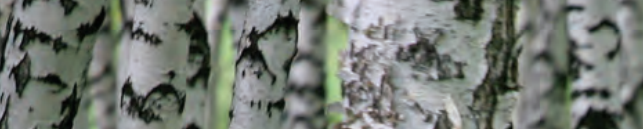

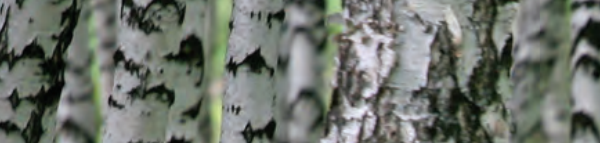

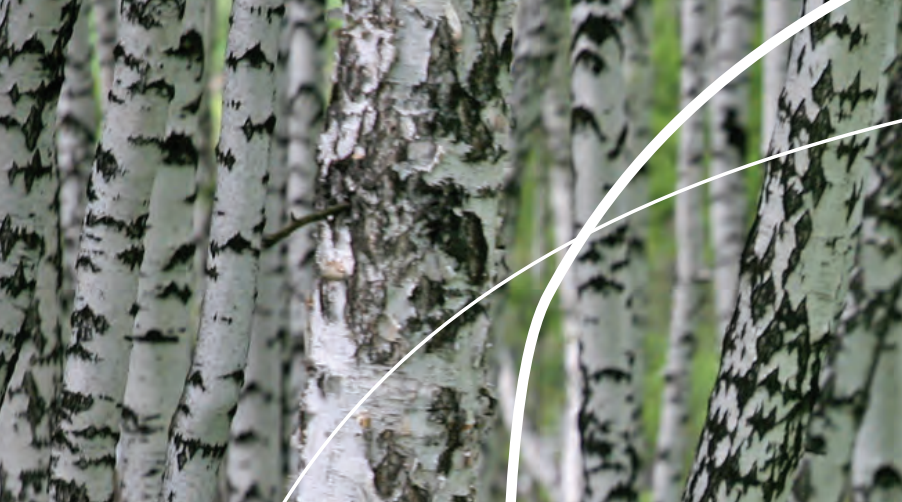

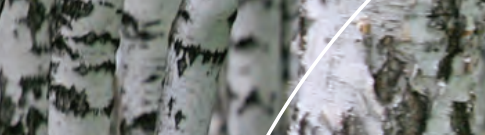
2. $y=0$ $7=1+x^{2}$ 74 W. (x) 10 20.7.

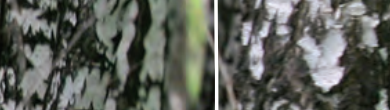
4 in 

4 norden 



\section{Best Available Techniques (BAT) in solid biomass fuel processing, handling, storage and produc- tion of pellets from biomass}

Jenny P. Lindberg och Jukka Tana, ÅF-Industri Ab 
Best Available Techniques (BAT) in solid biomass fuel processing, handling, storage and production of pellets from biomass

Jenny P. Lindberg och Jukka Tana, ÅF-Industri Ab

ISBN 978-92-893-2400-7

http://dx.doi.org/10.6027/TN2012-550

TemaNord 2012:550

(C) Nordic Council of Ministers 2012

Layout: Hanne Lebech

Cover photo: Image Select

This publication has been published with financial support by the Nordic Council of Ministers. However, the contents of this publication do not necessarily reflect the views, policies or recommendations of the Nordic Council of Ministers.

\section{www.norden.org/en/publications}

\section{Nordic co-operation}

Nordic co-operation is one of the world's most extensive forms of regional collaboration, involving Denmark, Finland, Iceland, Norway, Sweden, and the Faroe Islands, Greenland, and Åland.

Nordic co-operation has firm traditions in politics, the economy, and culture. It plays an important role in European and international collaboration, and aims at creating a strong Nordic community in a strong Europe.

Nordic co-operation seeks to safeguard Nordic and regional interests and principles in the global community. Common Nordic values help the region solidify its position as one of the world's most innovative and competitive.

\section{Nordic Council of Ministers}

Ved Stranden 18

DK-1061 Copenhagen K

Phone (+45) 33960200

www.norden.org 


\section{Content}

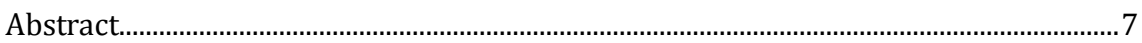

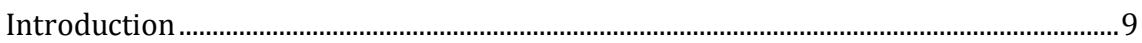

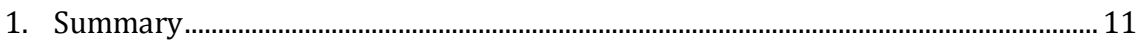

2. General information.............................................................................................. 13

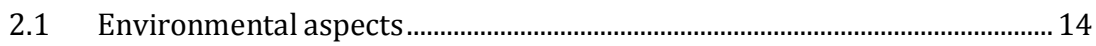

3. Existing fuels and standardization ...................................................................... 17

3.1 Solid biomass in the Nordic countries ............................................................ 17

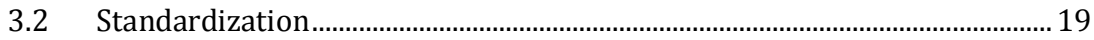

3.3 Forest fuel.................................................................................................... 21

3.4 Cultivated biomasses and agricultural residues ........................................... 25

3.5 Processed solid biofuels.............................................................................. 30

4. Biomass processing, handling and storage.................................................................. 33

4.1 Harvesting, natural drying and other processes at growing site -

Forest fuels .......................................................................................................... 33

4.2 Handling, Natural drying and other processes at growing site -

Cultivated biomass and agricultural residues................................................. 39

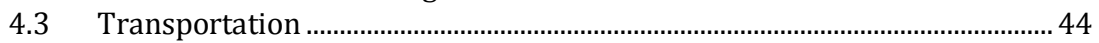

4.4 Handling and storage at terminals and at the point of use............................ 45

4.5 Biomass dewatering and drying at industrial scale......................................... 59

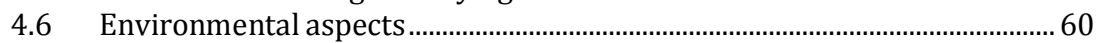

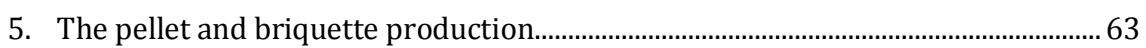

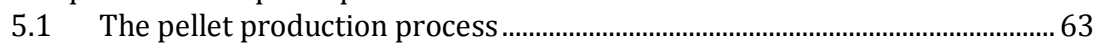

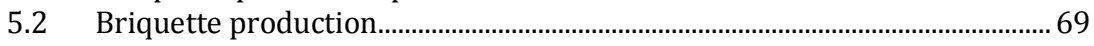

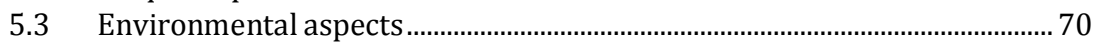

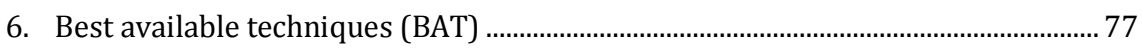

6.1 Harvesting, natural drying and other processes at growing site .................. 77

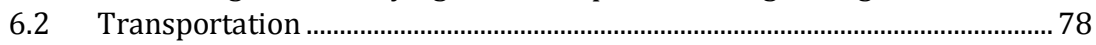

6.3 Handling and storage at terminals and at the point of use............................ 79

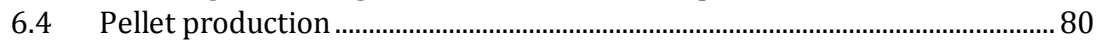

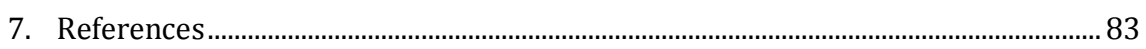

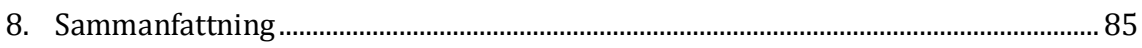





\section{Abstract}

The Nordic Council of Ministers, the BAT Group under the Working group for sustainable consumptionand production (the HKP-group) has requested to prepare a report on Best Available Techniques (BAT) in solid biomass processing, handling, storage and production of pellets from biomass in the Nordic countries.

The project aims to provide information for operators, environmental consultants and competent environmental authorities on what is considered BAT, as defined in the IPPC directive (2008/1/EC), in biomass processing and handling as well as the production of pellets from biomass. The Nordic countries are in the leading position in questions regarding handling solid biomass, especially Sweden and Finland in the forest segment and Denmark in the agricultural segment.

The project describes the present status of used technologies in the different steps of handling, preparing and refining solid biomass in the Nordic countries. Different techniques will generate different environmental impacts. Specific processes in the production chain, such as manufacturing of pellets, biomass drying or large-scale biomass storage do also contribute with emissions to air, water and soil. The focus of this study has been to locate these disturbances in the biomass process chain and present information in how to build up proper systems with reduced environmental impacts.

Tina Schmidt,

Chairperson, the Nordic NCM BAT-group 



\section{Introduction}

The Nordic Council of Ministers, the BAT Group under the Working group for sustainable consumptionand production (the HKP-group) has requested ÅF-Industry AB in Sweden together with ÅF Energy Oy in Finland to prepare a report on Best Available Techniques (BAT) in solid biomass processing, handling, storage and production of pellets from biomass in the Nordic countries.

\section{Objective}

With the increasing use of biomass fuels the varieties of sources for biomass have expanded to almost all possible combustible matter with biological origin. The increasing scale in solid biomass fuel production and utilization at the combustion plants of the wide variety of biomass fuels have contributed to littering, dust, odor and noise emissions of the production chain. Specific processes in the production chain, such as manufacturing of pellets, biomass drying and large scale biomass storage can have also direct emissions to air, water and soil. When this segment has increased over time the environmental impacts also increases and a need for more and liable information has occurred.

Therefore the Nordic Council of Ministers has decided to initiate a project to define the best available techniques for biomass fuel processing, handling and storage as well as the production of pellets in order to investigate the techniques and practices available to reduce the emissions of the biomass fuel chain to minimum. EU has decided to revise the current BREF-document for Large Combustion Plants (LCP $\mathrm{BREF}$ ), where this subject is handled today. The result from this project may act as an input to the new BREF-document.

The project aims to provide information for operators, environmental consultants and competent environmental authorities on what is considered BAT, as defined in the IPPC directive (2008/1/EC), in biomass processing and handling as well as the production of pellets from biomass.

\section{Scope}

The Nordic countries are in the leading position in questions regarding handling solid biomass, especially Sweden and Finland in the forest segment and Denmark in the agricultural segment.

The scope of this project is to map out and present status of used technologies in the different steps of handling, preparing and refining solid biomass in the Nordic countries. Different techniques will generate different environmental impacts. The focus of this study has been to 
locate these disturbances in the biomass process chain and present information in how to build up proper systems with reduced environmental impacts.

\section{Approach}

The project team has great experience in implementation and optimization projects as well as more technical and environmental studies of biomass handling and refining systems. From this a natural connection exists between the project team and different biomass handling and refining companies, an important base for this study. Besides environmental and statistical agencies have been an input to given figures in this report.

\section{Team of consultants}

The following consultants have contributed to the report:

- Anita Jacobsson, ÅF

- Anna Liljeblad, ÅF

- Göran Hed, ÅF

- Jenny P. Lindberg (Project Manager), ÅF

- Jukka Tana, ÅF

- Markku Raiko, ÅF

- Sean Walsh, ÅF

- Sini Pitkäranta, ÅF

- Per Lundkvist, ÅF

\section{BAT Group}

The BAT project has been follow and commented by the Nordic BAT Group. The members of the BAT Group are:

- Bo Jansson, Swedish Environmental Protection Agency

- Egil Strøm, Climate and Pollution Agency, Norway

- Eyd Eidesgaard, Environment Agency of Faroe Islands

- Jaakko Kuisma, Regional State Administrative Agency for Southern Finland

- Sigurdur Ingason, Environment Agency of Iceland

- Susanne Särs, Environmental and Health Protection Agency of the Aland Islands

- Tina Schmidt, Danish Environmental Protection Agency 


\section{Summary}

The demand for solid biomass for energy purpose has increased strongly the recent decades, and there is no sign of recession neither in the Nordic countries nor Europe. When EU presented The Climate Change action plan to reduce the need from fossil fuels biomass was an obvious candidate to take a bigger part in the renewed energy mix. From being kind of a byproduct from the local forest industry, even hard to get rid of in some cases, the solid biomass now is a spectrum of well paid products worth to be shipped long distances. Energy forest and cultivated biomass are products developed just for energy purpose; stumps, tops and branches are now worth to collect in the forest, to be fuels in the energy balance.

The increasing share of solid biomass, in a wide range of origin that is taking part in energy production chain has led to disturbances in the local environment. Littering, dust, odor and noise emissions are not uncommon where biomass is handled. Specific processes in the production chain, such as manufacturing of pellets, biomass drying or large-scale biomass storage do also contribute with emissions to air, water and soil. Environmental aspects in this study will focus mainly on these local emissions and impacts.

The solid biomass included in this study has been divided into three sections; forest fuel, cultivated biomass and agricultural residues and processed solid biomass, see Figure 1. Peat is specifically excluded in this study.

Figure 1. Schematic description of biomasses included in this study

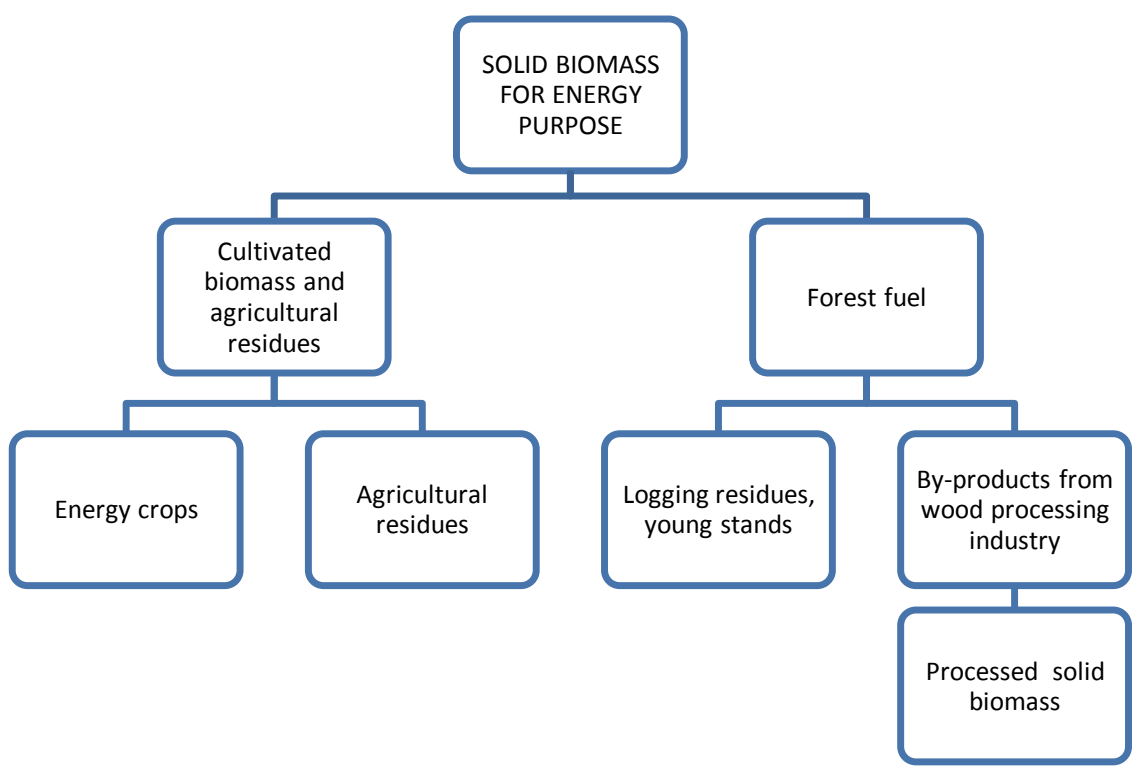


Statistical figures show how much solid biomass, for energy purpose, that was used in the Nordic countries in 2010; Denmark had about 28 TWh biomass in their total energy supply, Finland 87 TWh, Norway 15 TWh and Sweden 127 TWh. Iceland's biomass share was negligible. The driving force for harvesting forest is normally utilization in the sawing or pulp and paper industry. The part of the trees which is rejected by these industries is commonly used for energy purposes. An example is logging residues; it includes for example tops, branches, bark and young stands. When wood residues are utilized, ashes generated from the combustion need to be recycled to the forest to prevent the loss of nutrients in the soil.

After harvesting the main methods for production of biomass chips are chipping or crushing at the road side, at a logistics terminal, or at the point of use.

Densifying dried biomass into pellets and briquettes is a way of making biomass more attractive for various end users. The lower moisture content results in a high energy level and the high energy density compared to unprocessed biomass makes these products very suitable for transport.

Biomass for energy purposes can also be obtained from the agricultural sector and the most significant sources are cultivated biomass (energy crops) and agricultural residues (e.g. straw).

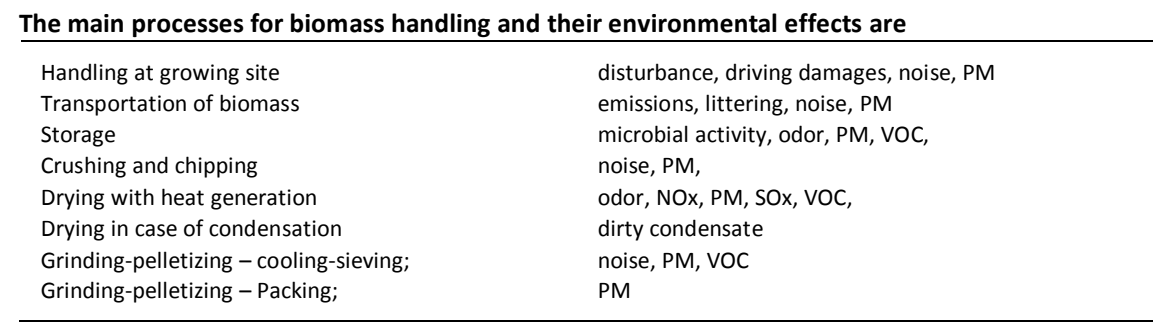

PM (particulate matter) - Dust emissions

VOC - Volatile organic compounds emissions 


\section{General information}

The Nordic countries have a traditionally high share of biomass in their energy mix for heat and power production. The renewable energy targets for EU members make biomass an even more desirable product. Several research programmes are going on in how to use land the most effective way and how to develop fast growing forest and crops for energy purpose. The growing out-take from the nature has to be done in a sustainable way; this is preferably done with best available technique in combination with least environmental impacts, in every step.

The Nordic countries have a good position to produce domestic biomass for heat and power production and for forest industry. In Figure 2 a comparison in energy supply between the different countries is presented, to get a grip of the countries' different energy demands. The figure also shows the total energy supply and sources in the Nordic countries 2010.1, 2, 3, 4, 5, 6

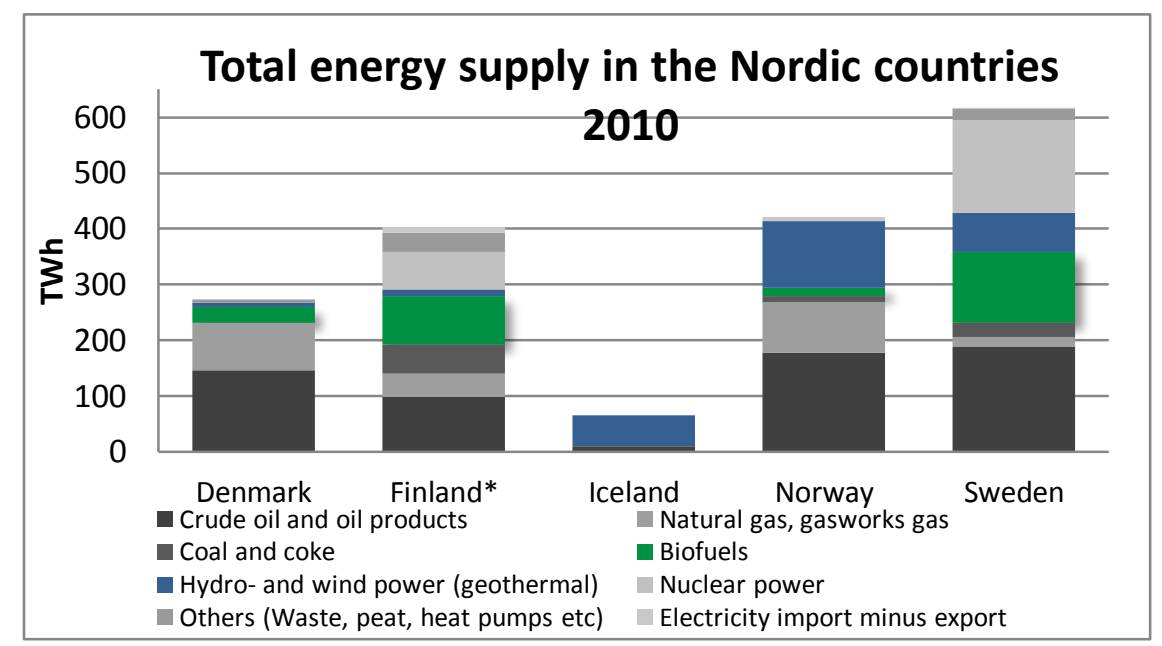

\footnotetext{
1 Energy Statistics 2010, Danish Energy Agency.

2 Statistical Yearbook of F orestry 2011, Metla.

${ }^{3}$ Statistics Finland.

4 National Energy Authority of Iceland, 2010.

5 Statistics Norway.

${ }^{6}$ Statistics Sweden and Swedish energy agency.
} 
Denmark has about 10\% (28 TWh) biomass in their total energy supply, Finland has 22\% (87 TWh), Norway has only 4\% (15 TWh) and Sweden is taking the leading position with $21 \%$ (127 TWh). Iceland's biomass share is negligible.

\subsection{Environmental aspects}

When the material flow increases and different forms of biomass occurs in our traditional energy system, new chains and techniques for producing different kinds of biomass are developed and the environmental impacts that follows have to be clarified. Littering, dust, odor and noise emissions are not uncommon where biomass is handled. Specific processes in the production chain, such as manufacturing of pellets, biomass drying and large-scale biomass storage do have direct emissions to air, water and soil. Environmental aspects in this study will focus mainly on these local emissions and impacts.

\section{Global warming}

In a more global perspective burning of biomass is not defined as a source of green house gas emissions. That means it not generating $\mathrm{CO}_{2-}$ emissions impacting on the balance of green house gases; technically the impact is considered already in the calculations of wood capital changes.

The harvesting and transportation of forest energy do often generate fossil $\mathrm{CO}_{2}$-emissions due to fuel consumption but their share is only $2-3 \%$ of the energy content of the produced fuel. ${ }^{7}$ Long time storage of chips also increases green house gas emissions to some extent because chips start to disperse at the storage places.

Table 1 presents an estimation of greenhouse gas balances with and without the harvesting of energy wood. In general it can be considered that the impact of harvesting energy wood is relatively small on the greenhouse gas balance of forests. ${ }^{8}$

Table 1. Annual differences in the carbon sink between alternatives where the energy wood is harvested or not harvested.

\begin{tabular}{lccccc}
\hline Karvested or not harvested. & Kyoto & $\mathbf{2 0 1 0}$ & $\mathbf{2 0 1 5}$ & $\mathbf{2 0 2 0}$ & $\mathbf{2 0 3 0}$ \\
\hline Energy wood is not harvested & 20,7 & 21,5 & 28,5 & 29,5 & 44,6 \\
Energy wood is harvested & 18,6 & 19,3 & 26,0 & 26,8 & 41,5 \\
\hline
\end{tabular}

Greenhouse gas balance milj. tonnes $\mathrm{CO} 2$-equivalents. The harvesting amount of energy wood in 20104 milj m3/a increasing steadily to 15 milj m3/a in 2030.

${ }^{7}$ Hakkila, 2004

8 Kuusinen \& Ilvesniemi 2008. 
The annual difference in the carbon sink between the two alternatives is in its maximum at 2030. Based on this estimation it is very probable that the biomass collected as logging waste (stubs, branches and needles) does not make a threat to the forests as a net carbon sink.

\section{Effects on landscape}

Effects of harvesting forest residues on landscape are not well examined. One questionnaire study has been performed in Finland about the issue. According the results harvesting logging residues has had positive effect on landscape and recreational of the forests. Most of the respondents answered either "landscape and environment will improve" or "there's no effect." 9

Recovery of small trees and logging waste mainly be considered comfortable and passable and to improve the recreation use of the forests. There is, however, information what is the amount of the logging wastes to be collected before the positive landscape effects are reached. There is also a possibility that the effects can be negative if large logging waste stacks are stored by the roads. Also the hoisting of stubs and their traces as well as the stub stacks can be considered impacts to the landscape. The main impacts for the landscape are storing of logging wastes and stubs. It would be better for the landscape to transport the logging wastes off from the site and roadside as soon as possible and store them for example at the chipping terminal. Impacts to the landscape could also be improved if the chipping takes place at the terminal or site of use decreasing the noise and esthetic impacts. The increased use of engines and machines also generally increases the damages of terrain and trees which can be negative impacts. The point of harvesting time can affect the disruptively. In order to minimize the noise impacts the harvesting of logging wastes and stubs, the chipping and the transportation would be good to arrange when the recreational activities are at the minimum, late autumn or winter time. This on the other hand can have a restrictive impact on the harvesting itself. 



\section{Existing fuels and standardization}

\subsection{Solid biomass in the Nordic countries}

The solid biomass included in this study has been divided into three sections. Peat is specifically excluded in this study.

\section{Forest fuel}

- Wood based biomass fuels and forestry residues e.g. rejected tops and branches, young stands, chips, stumps

- Industry residues from forest and food industries and clean wood waste, e.g. saw-mill rejects as bark and saw chips

\section{Cultivated biomass and agricultural residues}

- Energy crops as willow, reed canary grass and hemp

- Agricultural residues as straw and seeds coats

\section{Processed solid biomass}

- Pellets and briquettes from biomass

Properties of some selected solid biomass are shown in Table 2. For more detail information see standard document EN 14961-1, Annex B.

\begin{tabular}{|c|c|c|c|c|}
\hline Biomass & $\begin{array}{r}\text { Calorific value } \\
\text { [MWh/tonne] } \\
\text { (DS) }\end{array}$ & $\begin{array}{r}\text { Moisture } \\
\text { content } \\
\text { [weight-\%] }\end{array}$ & $\begin{array}{r}\text { Ash content } \\
\text { [weight-\%] } \\
\text { (DS) }\end{array}$ & $\begin{array}{r}\text { Bulk density } \\
\mathrm{kg} \mathrm{DS} / \mathrm{m} 3\end{array}$ \\
\hline \multicolumn{5}{|l|}{ Forest fuel } \\
\hline Wood chips and sawmill residues & $2-4,6$ & $8-60$ & $1.5-3$ & $200-350$ \\
\hline Logging residues, Stumps & 2,6 & $35-55$ & $1-5$ & $200-350$ \\
\hline Wood pellets and briquettes & 4,7 & $9-10$ & $0,4-0,8$ & $550-770$ \\
\hline \multicolumn{5}{|l|}{ Cultivated biomass } \\
\hline Willow & $\begin{array}{r}2,2 \\
4\end{array}$ & $10-15$ & $3-7$ & \\
\hline Reed canary grass & 4 & $10-15$ & $3-1$ & $200-300$ \\
\hline Hemp & & $15-15$ & $1,6-6,3$ & Low \\
\hline
\end{tabular}

DS-dry substance

10 Strömberg B., Handbook of fuels (Bränslehandboken), 2005.

11 IPCC, Revised 1996 Guidelines for National Greenhouse Gas Inventories. Reference Manual (Vol. 3), Energy, 1997. 
To define commonly used solid biomass in Nordic countries an overall statistical inventory was made for the different countries.

\section{Denmark}

In 2010 Denmark had a total production of primary energy of $272 \mathrm{TWh}$, and 36 TWh of those had its origin in renewable sources. Biomass currently accounts for approximately $75 \%$ of the renewable-energy sector, mostly in the form of straw, wood and renewable wastes, while biogas accounts for less. Consumption of biomass for energy production in Denmark has more than quadrupled between 1980 and 2005. A further increase is expected primarily due to the policy agreement (the Biomass Agreement) from 1993 and the policy agreement from February 2008 on the increased use of straw and chips at the large co-generation plants. At the same time, the consumption of biomass continues to rise as a source of energy for the supply of heat in district-heating plants and in smaller installations for households, enterprises and institutions.

\section{Finland}

The total energy consumption in Finland 2010 was 403 TWh. Biomass covered 87 TWh of the total energy consumption and was the next significant energy source after oil products.

The main potential to increase the use of biomass in Finland is related to the forest residues. Finland has a significant biomass potential. It is possible to produce forest residues in the form of logging residue chips, stumps or chopped fuel from final felling and in the form of chipped small size wood from young stand management and thinning areas. The amount of logging residues generated at the felling stands varies greatly site by site. Logging residue chips generated at the final felling of spruce stands have the best potential among forest biomass for producing energy at the competitive price in Finland. For spruce stands, the yield of logging residues is more than twice as much as for pine and birch stands. Nowadays also stumps of the spruce stands are exploited at final felling.

\section{Iceland}

Primary energy use by Iceland has increased by large amounts in the last few decades. The primary energy use in 2010 was almost $210 \mathrm{GWh}^{12}$ per capita, which is among the largest in the world. The proportion of this provided by renewable energy sources exceeds most other countries, nowhere else does geothermal energy play a greater role in proving a nation's energy supply. Around 15\% of the primary energy used in Iceland is imported, and $85 \%$ is produced domestically. The main types of energy are hydropower, geothermal, oil and coal.

12 The National Energy Authority. 
A wood chip boiler has been built in Hallormsstadur and it is the first one of its kind and scale. The $500 \mathrm{~kW}$ boiler provides hot water mainly for public premises. There are plans to connect all residential houses to the heating network. ${ }^{13}$

\section{Norway}

Almost 50\% of Norway's energy consumption (totally 245 TWh in 2010) is based on hydropower. That unique position with rich supply of renewable energy has during the decades formed Norway's energy politics. Even as a non member of EU Norway has ambitious targets to increase their biomass share. 2006 the biomass consumption was 14.5 TWh and the target for 2020 is to increase the biomass use with 14 TWh. ${ }^{14}$

\section{Sweden}

In 2010 the total energy supply in Sweden was about 615 TWh and the energy system includes a relatively big share of biomass, 127 TWh which corresponds to $21 \%$ biomass. In the 1980 s the biomass use in the Swedish energy system was only about $10 \%$.

Biomass is used mainly in the forest industry but also in district heating plants, for electricity production and heating of residential buildings. Most of the increase in the use of bio energy is linked to increased district heating, electrical production and industry investments. Although use is also increasing in the residential and transport sectors.

\subsection{Standardization}

The Technical Specification of "Fuels Specification and Classes" is one of the standards that have been produced by the Solid Biofuel Working group, TC 335 in the area "Fuel Specifications, Classes and Quality Assurance". According to the mandate given for the standardization work, the scope of the CEN/TC 335 only includes solid biofuels originating from the following sources:

a. products from agriculture and forestry

b. vegetable waste from agriculture and forestry

c. vegetable waste from the food processing industry

d. wood waste, with the exception of wood waste which may contain halogenated organic compounds or heavy metals as a result of treatment with wood preservatives or coating, and which includes in

\footnotetext{
13 Skógarorka.

${ }^{14}$ Bioenegi i Norge - potentialer, marknader og virkemidler, Østlandsforskning.
} 
particular such wood waste originated from construction and demolition waste

e. fibrous vegetable waste from virgin pulp production and from production of paper from pulp, if it is co-incinerated at the place of production and heat generated is recovered

f. cork waste

Biomass is produced from a variety of plant materials with differing chemical and physical characteristics. Furthermore, production processes and biomass handling largely impact the biomass quality. This results in biomass being a heterogeneous fuel, and this has to be considered e.g. in contracts within the biomass chain, as the value of the fuel depends on its characteristics. The creation of European quality standards for solid biofuels aims at facilitating the involvement of economic operators in the solid biofuel industry.

In Figure 2 a biomass classification map is shown.

Figure 2. Classification of woody biomass - Source Eija Alakangas, VTT

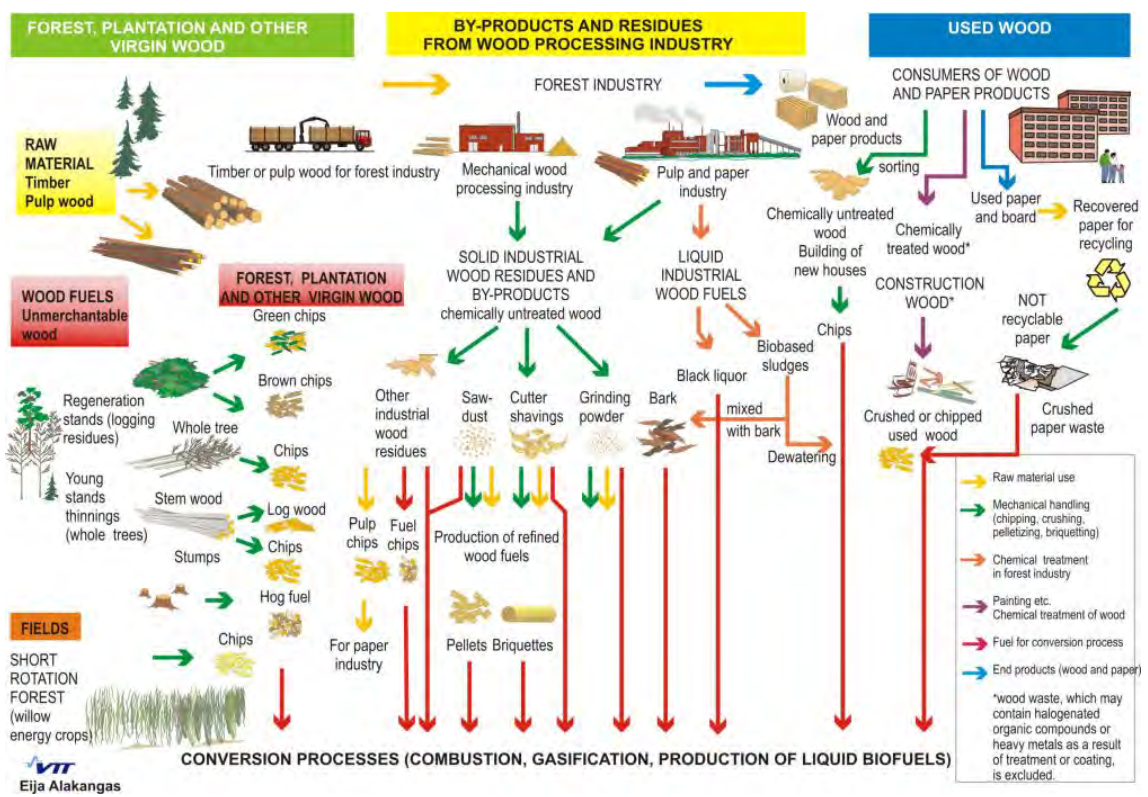

EN 14961 is a multipart standard consisting of 6 parts. The first part (General requirements) provides the framework for a common and clear classification method for solid biofuels. The other 5 parts are product standards for commonly traded forms of biofuels such as wood and nonwood pellets, wood briquettes, wood chips and firewood.

EN 15234 is a quality assurance for solid biofuels, a multipart standard. This standard defines the basis of a quality assurance system for the whole biofuel supply chain. It includes general definitions of specifications necessary for agreements between actors along the supply chain, 
needs for documentation and traceability and critical control points. In addition to general guidance (part 1), specific parts (corresponding to EN 14961) have been developed. Part 2 for example gives an overview on critical quality issues specifically for the wood pellets supply chain. ${ }^{15}$

\begin{tabular}{ll}
\multicolumn{2}{l}{ Table 3. Examples of some interesting European standards for solid biofuels ${ }^{\mathbf{1 6}}$} \\
\hline CEN/TC 335 Solid biofuels & \\
\hline EN 14588:2010 & Solid biofuels - Terminology, definitions and descriptions \\
& Solid biofuels - Fuel specifications and classes - \\
EN 14961- & Part 1: General requirements \\
1:2010 & Part 2: Wood pellets for non-industrial use \\
2:2011 & Part 3: Wood briquettes for non-industrial use \\
3:2011 & Part 4: Wood chips for non-industrial use \\
4:2011 & Part 5: Firewood for non-industrial use \\
6:2011 & Part 6: Non-woody pellets for non-industrial use \\
EN 15234-1:2011 & Solid biofuels - Fuel quality assurance - \\
& Part 1: General requirements - \\
EN 15210-1:2009 & Solid biofuels - Determination of mechanical durability of pellets and bri- \\
& quettes - Part 1: Pellets \\
\hline
\end{tabular}

\subsection{Forest fuel}

Finland and Sweden have a large domestic supply of forest-based fuels and also a large forest industry. Denmark, on the other hand, is a more agriculture based country regarding biomass supply. Only 14\% (591,000 ha) of Denmark's land area was covered by forest and other wooded land in 2010. In Finland 77\% (23,269,000 ha) and in Sweden $76 \%$ $(31,247,000 \mathrm{ha})$ were covered by forest and other wooded land in $2010 .{ }^{17}$ Norway was covered with $37 \%(12,000,000 \mathrm{ha})$ forest and other wooded land the same year. ${ }^{18}$

The driving force for harvesting forest is normally utilization in the sawing or pulp and paper industry. This use of forest biomass is normally rather profitable as compared to other uses, and therefore the part of the wood that can be used for these purposes is regarded to have the highest value. The part of the trees which is rejected by these industries is commonly used for energy purposes.

The felling of trees preferably takes place during the period from January to March, when the moisture content is relatively low and the ground is frozen. Afterward, the trees that have been felled should be

\footnotetext{
15 The SolidStandards project, European Commission.

16 The European Committee for Standardization (CEN)

172011 annual Statistical Report on the contribution of Biomass to the Energy System in the EU27, AEBIOM, Brussels.

18 U.N. FAO, Global forest Resources Assessment Country Reports Norway, FRA2010/155.
} 
left in the forest during the summer to reduce the moisture content even further and to enable needles and small branches to detach. On the other side pest and herbal disease control is an important issue. For example there are some regulations in Finland for storing logs in summer time just because of the increased risk of forest damage. Decomposing of biomass starts immediately after harvesting if the biomass stays wet and part of its energy potential is lost. Drying is a good element to store the biomass.

Figure 3. The flow of wood based biomass in Sweden 2008

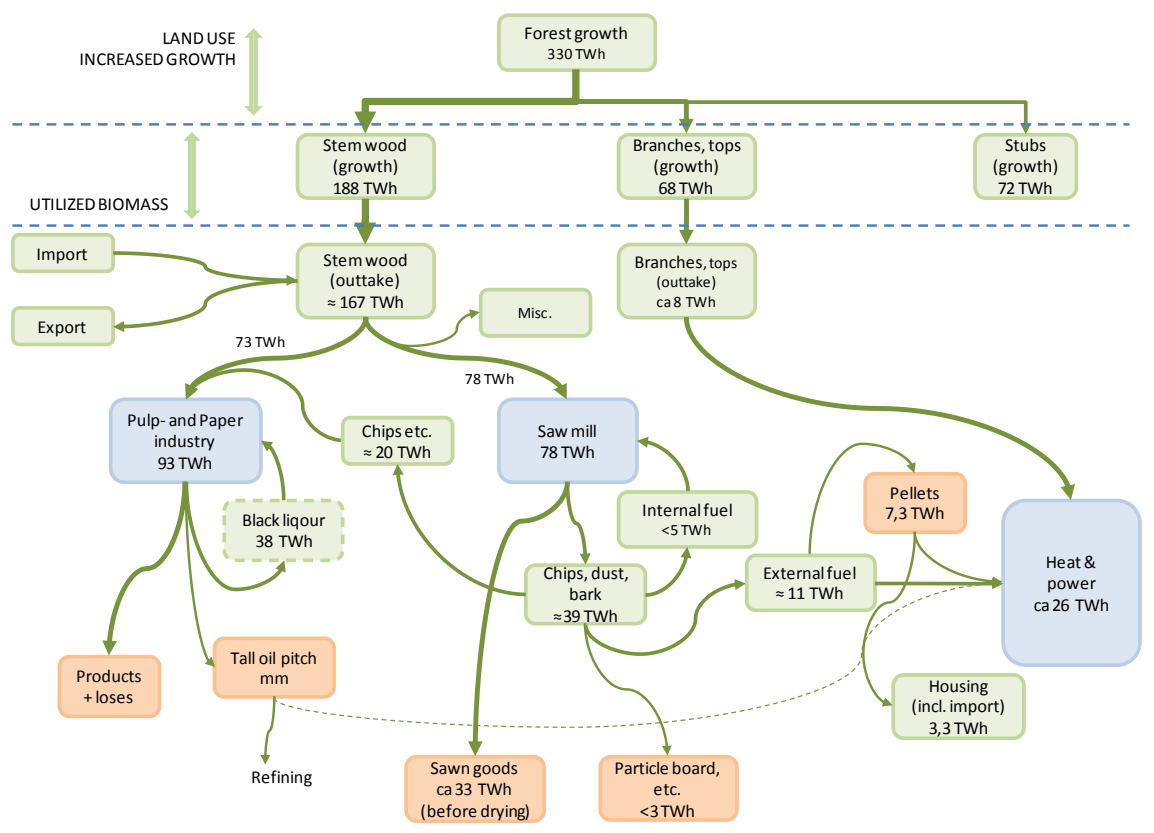

Figure 3 presents as an example from Sweden the different biomass flows from forest growth to different products and by-products.

A significant part of the stem wood is taken to the saw mill (approx. $50 \%$ ). At the sawing process great volumes of rest products arises and most of this biomass is used in the pellets industry and the heat and power generation. Private firing with solid biomass is excluded.

\subsubsection{Wood chips and sawmill residues}

Wood chips for energy purposes can be produced from e.g. top ends and other residues in the clear cuttings, from the thinning of young tree plantations, or from second grade trees which have been infected by rot or fungus, discolored or that cannot be used as commercial timber for other reasons. However, due to the increased demand for wood biomass, there is a tendency to chip whole logs of normal quality and not only second grade quality for energy purposes. 
Another main channel for the biomass is the sawmill residues. In the sawmill process with production of board and plank approx. 50\% of the timber ends up as by-products of different types, such as bark, saw dust etc. Figure 4 illustrates that process flow including descriptions of byprocess flows.

\section{Figure 4. General flow in a saw mill}

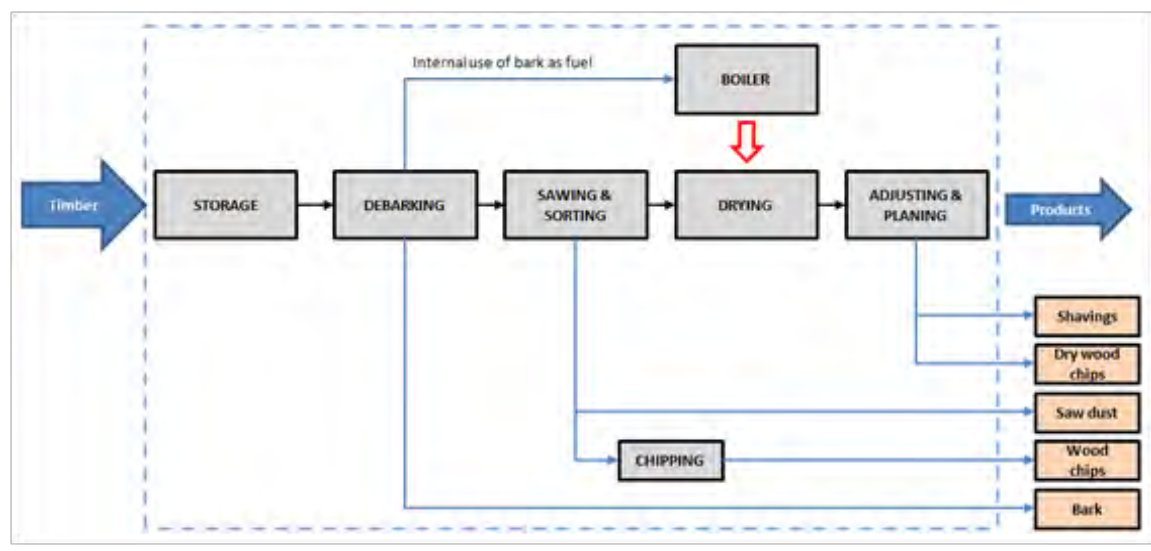

In the debarking step, the bark is removed from the log. Sawdust is produced in the sawing steps. It can be used in the pellet industry or in biomass mixes to district heating companies.

Some of the side parts and length adjustments are chipped to and sold to a pulp mill as raw material (pulp chips - without bark rests) or to the district heating industry as wood chips.

The final production step within sawmills, after drying, is the adjusting and for some products (not in all sawmills) planning. In the adjusting step sawing creates dry fuel-chips as by-product. In terms of volume this part is small as compared to the other streams of by-products from the earlier process steps. It is common to mix the dry fuel-chips with other by-product material (with higher moisture) and thereby reduce average moisture level of the by-products. When planning is a part of the production, the shavings share increases. The shavings can be used as a raw material for pellet production without any need for drying.

\section{Fuel quality of wood chips and saw mill residues}

High quality wood chips can only be produced from optimal raw material with a minimum diameter of five centimetres. ${ }^{19}$ Smaller diameters cause more ash, which means less convenience for the customer operat- 
ing the wood chips heating system. Rotten and musty wood as well as dirty or demolition wood, shrubs with small branches and whole trees are not suitable for production of high quality wood chips for small wood chips heating systems. Such raw materials can, however, be used to produce lower quality wood chips for larger biomass heating plants.

The moisture content of bark is usually above $50 \%$. A significant share in the sawmill industry ( $44 \%$ on a national level in Sweden) is used internally as fuel for drying purpose. The rest of the bark is sold and is often used as biomass mixes to district heating companies.

\subsubsection{Logging residues}

The logging residues include, for example, tops, branches, bark and young stands. Wood logging residues are rich in mineral nutrients and when wood residues are utilized, ashes generated from the combustion need to be recycled to the forest to prevent the loss of nutrients in the soil.20

\subsubsection{Stumps}

The technology used in stump extraction has not undergone any major changes since the 1980s. The developments in the field are mainly taking place in Finland. There has also been a significant research activity in the harvesting of forest fuels and stubs have been included in these research projects.

\section{Fuel quality of stumps}

The use of stumps as a fuel source has been increasing. Stumps from spruce trees are preferred as the amount of recoverable energy wood is higher due mainly to the root structure. The share of energy wood in the stumps in spruce predominant areas corresponds to 25 to $30 \%$ of the volume of the stems. ${ }^{21}$

Stumps have high concentrations of inorganic contaminants. It is primarily the soil type on the cutover and weather conditions before and during the harvest that determines the degree of contamination. Stumps that are harvested in early summer dry quickly. Storage is an effective way of reducing moisture and ash content in the stump wood. After three months of storage, moisture content may have decreased by 50 percent. ${ }^{22}$ The ash content can vary between 1 and $24 \% .{ }^{23}$ The ash con-

\footnotetext{
20 Thorsén Å., Björnheden R., Eliasson L., Efficient forest fuel supply systems - Composite report from a four year R\&D program 2007-2010, Skogforsk.

${ }^{21}$ Leinonen A., Impola R., Rinne S., - Harvesting of stumps for fuel, VTT Processes - Paper presented at the conference "Bioenergy in Wood Industry 2005."

22 Thorsén Å., Björnheden R., Eliasson L., (Efficient forest fuel supply systems - Composite report from a four year R\&D program 2007-2010, Skogforsk.
} 
tent can decrease to levels below $4 \%$ when stumps are stored for three months, if the stumps were extracted during the spring. It is important that storage time is considered in relation to both fuel quality and the total energy content in the stored stumps. Dry matter losses rise as storage time increases, due to attack by wood-decomposing fungi.

\subsection{Cultivated biomasses and agricultural residues}

Biomass for energy purposes can be obtained from agricultural sector and the most significant sources are cultivated biomass (energy crops) and agricultural residues (e.g. straw). Energy crops are those annual or perennial plants that are specifically cultivated to produce solid, liquid or gaseous forms of energy, including transport biofuels. These can be traditional crops such as oilseeds, cereals, sugar beet and new dedicated perennial energy crops - only planted for energy purposes - such as fast growing energy forest (e.g. willow), reed canary grass and others.

At present, the agricultural areas in the Nordic countries are almost exclusively used for plant cultivation for food, animal feed, and provisions or for animal husbandry. Only a small part is used for energy purposes. The climate conditions in different parts of the Nordic countries affect the choice of crops grown for energy production purposes.

In Figure 5 different biomass flows from agriculture growth to different products and by-products are shown, this example is taken from Sweden. 
Figure 5. Flows of biomass from the agriculture in Sweden

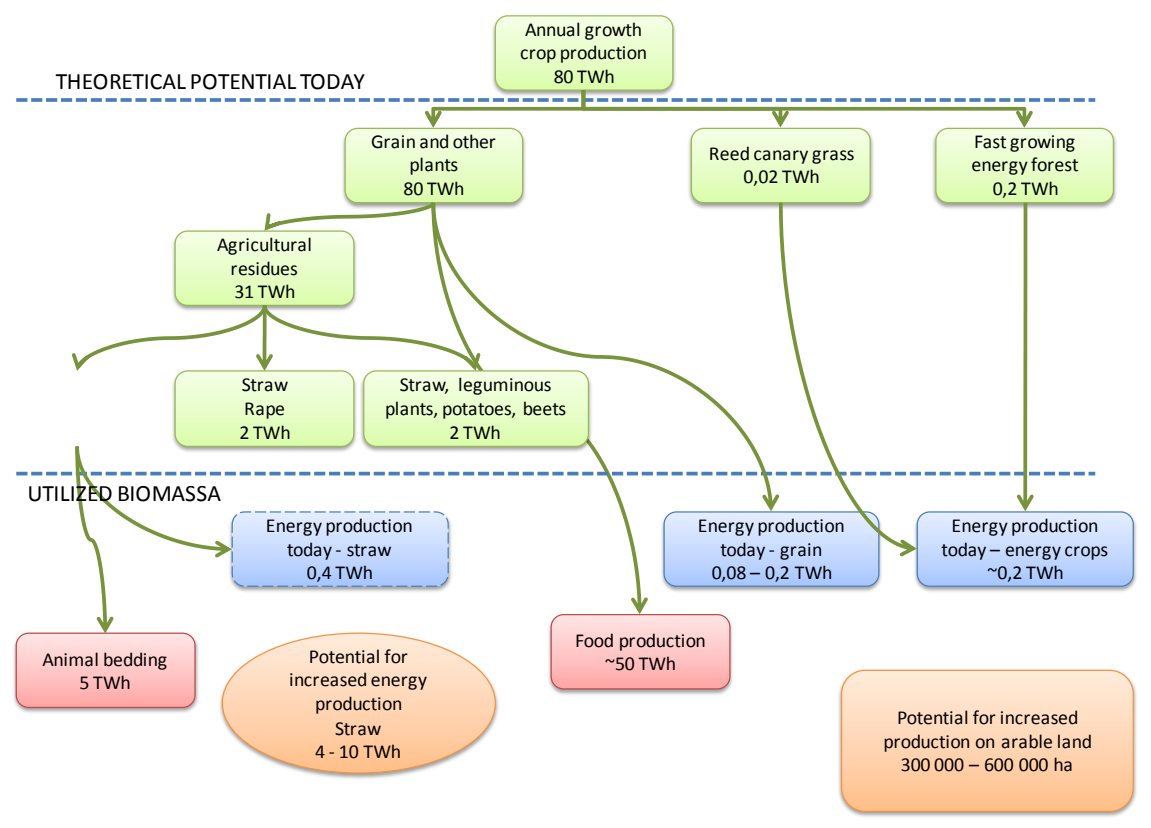

\subsubsection{Fast growing energy forest (Willow)}

Willow is a perennial agriculture crop that is cultivated for the production of willow chips for heat and power production. Willow may also be a potential raw material for the production of renewable transport fuels through gasification. There are a large number of species of naturally growing willow, totally around 300 , but only a few have a growing pattern that is suitable for fast growing willow plantations, so-called energy forest.

Willow has a large carbon mitigating potential and is fast growing. Another unique property is that some varieties of willow are capable of taking up cadmium from arable land which means that willow can be used as a cleaner of the ground and thus reduce the risk of increased cadmium concentrations in foodstuffs (provisions); however, the cadmium rich fly ash from combustion of cadmium rich willow should not be recycled to the plantations.

Results from AEBIOM and ENCORP projects indicate that around 15,500 hectares land) were used for willow in 2008 in the Nordic countries (Sweden and Denmark). ${ }^{24}$

242011 annual Statistical Report on the contribution of Biomass to the Energy System in the EU27 (2011), AEBIOM, Brussels. 


\section{Cultivation}

Willow is best suited for clays and organic nutrient fields and it requires large amounts of water when it grows. Willow grows rapidly during the second year after planting. Plantation normally takes place from March until June and it should, if possible started as early as possible in the spring when the weather and ground conditions permit. Early planting leads to better establishment and healthy growth during the first year. It is extremely important to control weeds during the establishment phase of willow, since weeds have a negative effect on the willow plants as they compete for light, water and nutrition.

\section{Fuel quality of willow chips}

Harvested willow chips are more or less equivalent to wood chips considering volume density and other fuel parameters. However, the size of willow chips is normally bigger, the share of fine particles is often lower, and the moisture content is usually higher. The moisture content is around $50 \%$. When willow chips and wood chips are compared with each other, willow contains higher proportion of cadmium and zinc. However, wood chips contain higher proportion of copper. The quantity of metals affects the handling of the rest product (ash).

\subsubsection{Reed canary grass}

Reed canary grass is a member of the Rhizome grass family. Common to all perennial Rhizome grass is that winter/spring harvesting is possible giving a shriveled and dry product under the conditions when dryness and/or frost causes the parts of the plant above ground to die off. Reed canary grass is of special interest in the Nordic countries since the crop can be grown on most soil types (however best on organic soil), and is not affected by the cold climate. Crop quality even improves during the winter as the presence of nutrients is reduced. Harvesting for energy use is preferred during the short period after the snow and ice have melted and before new growth begins. Reed canary grass is used in agriculture for feed but a minor part is also used for energy purposes.

Reed canary grass has been of particular interest in Finland. However, technological problems like handling and burning the fuel have recently reduced the level of interest. Generally, the area under cultivation in Finland has increased from 8,700 hectares in 200425 to 18,700 hec-

25 Econ Pöyry AS, (2007). The expanding Bio-energy Market in the Nordic Countries - Possibilities and Consequences, Commissioned by Nordic Energy Research, Denmark. 
tares in 2008. ${ }^{26}$ In Sweden, only 780 hectares were used for reed canary grass in 2008.27

\section{Fuel quality of reed canary grass}

Processed reed canary grass is found in the form of pellets, briquettes, powder, bales or as loose straw. Reed canary grass has a relatively high ash melting point in comparison with most other kinds of biomass. One of the main reasons for this is that some elements that cause a low ash melting point, e.g. potassium have leached out during the winter. Reed canary grass contains a considerably higher amount of sulphur, nitrogen, and chlorine as compared to wood fuel and wood pellets. This leads to high emissions of nitric oxides and sulphur oxides when combusting reed canary grass.

\subsubsection{Hemp}

Hemp is an annual crop that must be planted annually. Hemp has extreme fiber strength in comparison with other straw fuels used in the Nordic countries. The interest in hemp is not restricted to its use as an energy crop; its fiber can also be used for textiles, paper, insulation, and as strengthening in concrete, polymeric materials etc. The hemp seeds may also be pressed for oil, used directly in food products, or as animal feed.

According to AEBIOM and ENCROP projects only about 390 hectares land in the Nordic countries (Sweden) were used for hemp in $2008 .{ }^{28} \mathrm{In}$ Sweden, hemp has been grown as an energy crop since 2003. The difference with other crops is that only EU certified "industrial hemp" varieties can be used.

\section{Fuel quality of hemp}

Hemp intended for combustion is best without leaves, because the leaves contain high levels of potassium, sodium, and chlorine, elements that can cause problems in the boiler, e.g. sintering and build up with the risk of corrosion. The leaves also generate a great amount of ash. Hemp has two important disadvantages. Firstly it is far too dry to be fired as the only fuel in a boiler with a movable grate. Secondly it has a high volume, which leads to high storage and transport costs. One way of avoiding this is to blend hemp with other fuels, like wood chips.

\footnotetext{
262011 annual Statistical Report on the contribution of Biomass to the Energy System in the EU27 (2011), AEBIOM, Brussels.

272011 annual Statistical Report on the contribution of Biomass to the Energy System in the EU27 (2011), AEBIOM, Brussels.

282011 annual Statistical Report on the contribution of Biomass to the Energy System in the EU27 (2011), AEBIOM, Brussels.
} 
The technology for refining hemp has not yet been fully developed in terms of fiber separation, grinding, conditioning, pelletizing etc. Because hemp is an annual crop and frequently needs to be handled in bale forms it is expensive to produce hemp for large scale energy purposes. Hence, growing hemp solely for energy purposes is not a realistic option.

\subsubsection{Straw from various crops (e.g. wheat, rape)}

Straw is a by-product from the growing of various crops (e.g. wheat, rape). After the 1973 oil crisis, straw was started to be used as fuel for heating production. Of the total production of straw, only a minor part is used for energy purposes. The major part is used in agriculture for soil amelioration by ploughing the straw back or by using it for feed, grain drying etc.

Straw is not an international commodity in the same way as wood chips and wood pellets. Straw is primarily sold locally and there will often be a significant price difference between the various parts of the Nordic countries. Denmark has taken the front position in combustion technologies using straw, both in small scale, medium scale CHP and large scale power plants.

\section{Fuel quality of straw}

Straw occurs in the form of powder, pellets, bales, or loose straw. Straw as fuel has a relatively high ash content, varying between 2.5 and $10 \%$ depending on the origin and technology by which it is burned. A problem with straw is that the ash starts to melt at a relatively low temperature, around $800-1,000^{\circ} \mathrm{C}$, i.e. at a lower temperature than for most other types of biomass fuels. Straw used for fuel purposes usually contains $14-20 \%$ water. Straw has a high content of chloride and alkali metals that can cause problems like corrosion in super-heaters or slag formation and blockages in different parts of the boilers. Therefore, straw which has been lying in the field after the harvest and has become thoroughly wetted by rain (known as grey straw) is preferred, since the alkali levels in the straw thereby is reduced. ${ }^{29}$ Furthermore, the grey straw is easier to ignite. The same effect can be reached through straw washing at a temperature of $50-60{ }^{\circ} \mathrm{C} .30$

\footnotetext{
${ }^{29}$ Berg M., et al., (2007), Pre-study - compilation and synthesis of knowledge about energy crops from cultivation to energy production, Värmeforsk, (Swedish).

${ }^{30}$ Strömberg B., (2005), Handbook of fuels, Värmeforsk, (Swedish).
} 


\subsubsection{Grain and grain stalks}

Grain can be classified as wheat, barley, or oats. Grain has traditionally been grown for food proposes, and the use for energy purposes has been ethically questioned. The interest for using grain as fuel has been increasing in recent years, mainly on small farms. Grain can easily be fermented to produce ethanol.

\section{Fuel quality of grain}

There are relatively big differences in the quality of different types of grain as fuel. The quality of grain as fuel is affected by many factors, for instance, type of grain, the weather conditions during the year, and the cultivation measures. The ash melting point of grain is affected by both the elements contained in it and the mix of these elements.

\subsubsection{Oil-seed crops}

Oil-seed crops, e.g. rapeseed, soybean and sunflower can be converted into methyl esters. Rapeseed is one of the most widely grown energy crops in Europe. Rapeseed oil is produced by pressing the rapeseeds and then extracting the oil by steam and hexane. The by-product is a rapeseed cake, which can be used as a high protein animal feed. Rapeseed oil is used as raw material for producing RME (rape methyl ester) through esterification.

\subsection{Processed solid biofuels}

Densifying dried biomass into pellets and briquettes is a way of making biomass more attractive for various energy users. The lower moisture content results in a high energy level and the high energy density compared to unprocessed biomass makes these products very suitable for transport.

\subsubsection{Pellets}

The pellet is a processed biomass product and a European standard exists determines the different fuel quality classes and specifications for solid biofuel (EN 14961-1) and defining the pellet physical data (EN 14961-2). The European Pellet Council has also produced "Handbook for the Certification of Wood Pellets for Heating Purposes" based on EN 14961-2. The pellet product is intended as an easy handled biofuel for boilers in minor district heating systems, enterprises and private homes. Furthermore it enables the replacement of fossil fuel in large-scale oil and coal-fired boilers. 
Figure 6. Wood pellets

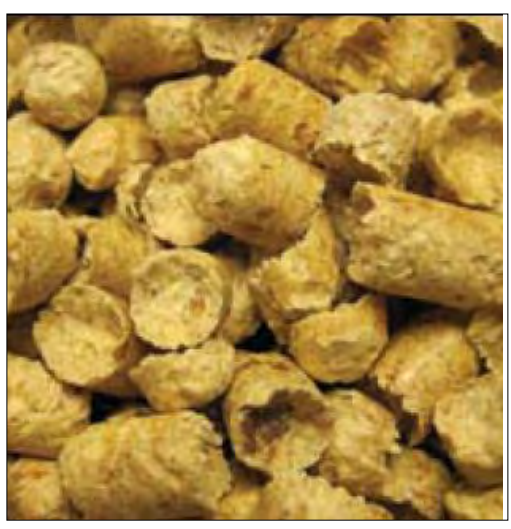

The low moisture content in pellets makes it very suitable for small boilers. A FGC (flue gas condensation) installation can be fairly expensive and this explains why dry fuel (as pellets) is chosen for small bio-boilers with high heat capacity.

Many large-scale oil, coal and co-fired boilers can be converted to pellet firing. This can be achieved without too expensive investments where a bio powder firing equipment is installed. This type of boilers does not have flue gas condensation so the low moisture content in pellets is therefore a desirable feature.

Table 4. Nordic production and consumption of biopellet [tonnes/yr] - 2008

\begin{tabular}{lrrr}
\hline Country & Production & Consumption & Comment \\
\hline Sweden & $2,200,000$ & $1,850,000$ & \\
Denmark & 135,000 & $1,100,000$ & \\
Finland & 370,000 & 150,000 & \\
Norway & 45,000 & 40,000 & Cap. $+450,000$ in 2011 \\
\hline
\end{tabular}

\subsubsection{Briquettes}

The briquette is a processed biomass product and standard exists defining its physical data (EN 14961-3).

The product is intended as an easy handled biofuel for furnaces in district heating systems and enterprises. Normally in the smaller cases with a exception in Sweden at the district heating system in Uppsala. For private homes the briquette is not suitable in automatic handling.

The production volumes was 2006 in Sweden 280,000 tonnes/yr, including parts based on non-wood material (e.g. peat). 


\section{Biomass processing, handling and storage}

This section gives a brief description of commonly used processes for processing, handling and storage of biomass in Nordic countries based on existing information, covering processes from production site to the point of use. Environmental aspects have been included in each process section whenever there has been available information on them.

$\begin{array}{ll}\begin{array}{l}\text { The main biomass handling steps with some environmental effects are } \\ \text { Harvesting }\end{array} & \begin{array}{l}\text { disturbance of eco system, driving damages, disturbances at } \\ \text { growing site, PM }\end{array} \\ \begin{array}{ll}\text { Noise } \\ \text { Storage }\end{array} \\ \begin{array}{l}\text { microbial activity, VOC, odor } \\ \text { emissions, PM, littering }\end{array} \\ \text { Handling and storage at the point of use } & \text { PM, noise, }\end{array}$

PM (particulate matter) - Dust emissions

VOC - Volatile organic compounds emissions

\subsection{Harvesting, natural drying and other processes at growing site - Forest fuels}

\subsubsection{Stem wood and logs}

\section{Harvesting and forwarding}

Harvesting is performed by using a harvester (a special machine, which grabs the tree and cuts it close to the roots) or manually by using a chain saw. Harvesters are preferred for large scale production as they greatly increase production rates, provide a much higher level of personnel safety, and minimize the amount of persons needed for the harvesting operation.

Modern harvesters are very advanced machines, capable of accessing difficult areas while maintaining good operator safety and comfort. They are also equipped with advanced technology for measuring the size of the tree and determining the most suitable log lengths according to the end users' requirements.

The stem of the tree will be used by sawmills, pulp industries or heat and power plants and is separated from the remaining parts (residues). 
This is performed by cutting away the top of the tree and all branches from the stem. The stem is then cut into log lengths that allow easy transport by road and which suit the processing equipment available at the end users site.

\section{Figure 7. A typical stack of logs close to the clear-cut}

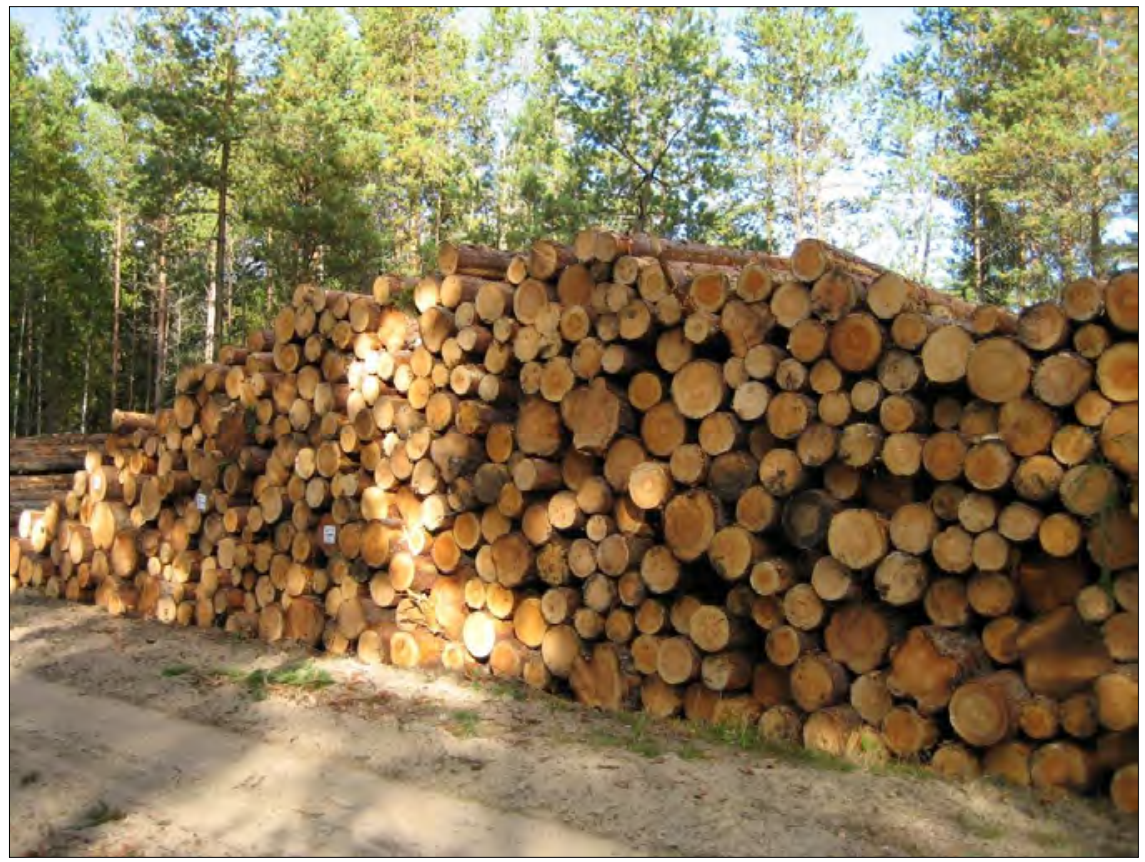

A forwarder is used to transfer logs from the harvesting site to a nearby road where they are stacked to await collection by log trucks, see Figure 7. Forwarders are based on the same technology as harvesters, but are more simple and equipped with a crane and trailer for collection and carrying the logs or residues. They can also be used to transfer residues to the road side where they are stacked to enable drying, see 4.1.2. The logs can be stored in the forest (or at a terminal) for drying reasons. For biomass chips production see 4.1.4.

\subsubsection{Logging residues}

\section{Harvesting, chipping, storage and bundling}

The Swedish Forest Agency has issued recommendations on harvesting methods that should be used in order to help maintain biodiversity in the forest during and after harvesting of logging residues. This has also been discussed in the research programs on forest fuels and their harvesting. According to the recommendations tops and branches should be collected in a manner that allows the majority of needles to remain in the forest, 
well spread across the harvesting area. The needles have a high concentration of nutrients and are therefore valuable to the forest's re-growth.

\section{Figure 8. Collecting residues at a Finnish harvesting site}

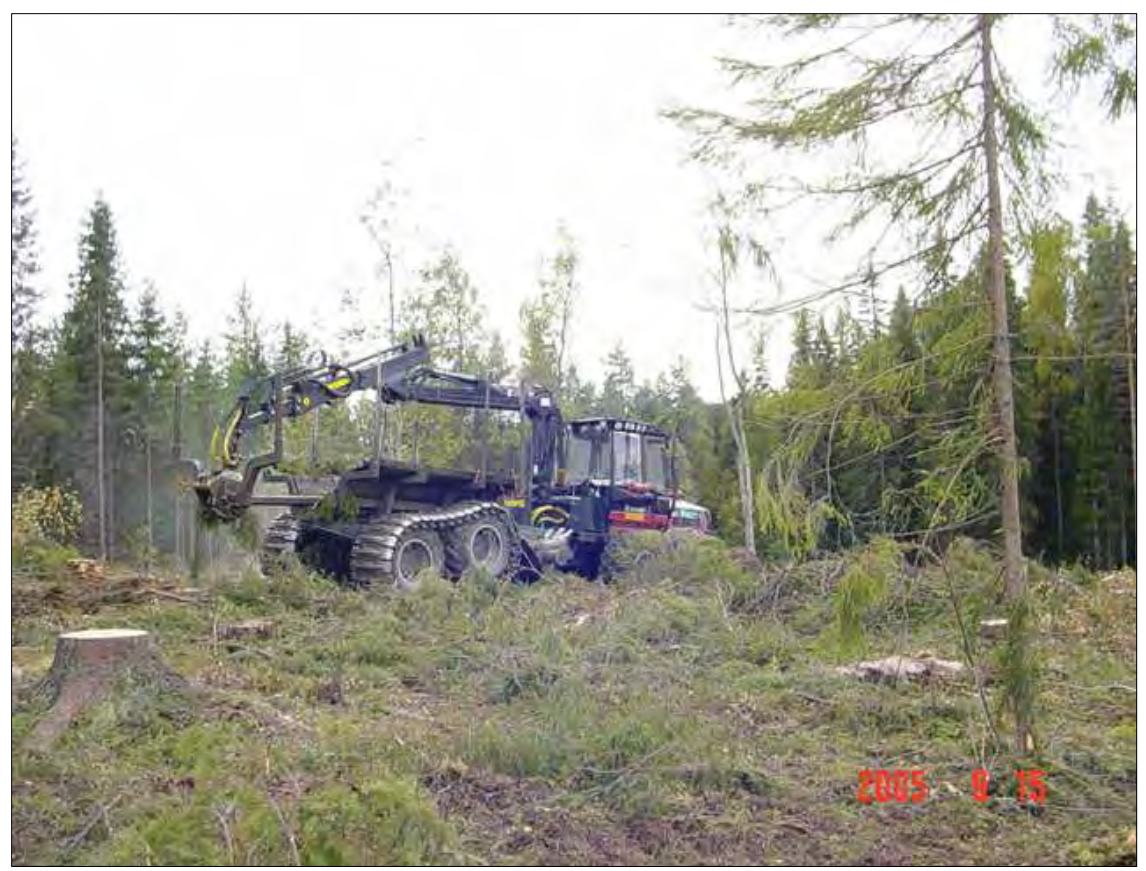

Primarily, the logging residues are gathered and stored in log piles at the roadside, but an alternative is to store them in piles at the clearing areas for subsequent gathering when the needles have fallen off and the material is dryer. The moisture content is normally around 50 and $55 \%$ directly after harvesting but declines when logging residues are stored in the field or at the roadside. Normally, logging residues will be left for some months in the clearings, then after some periods of raining (1 month - 1 year) most of water soluble components (alkalis, chlorides etc) will separate and drop down to the soil. The residue pile is then covered (only upside) by a light tarpaulin for drying the biomass. Then after one some months the biomass is dry and ready for transport. The transport lorries can have mobile crusher and the crushing can be done during loading. In the Nordic countries, piles should not be left at the site or at terminals after early autumn, because the moisture content will increase at this time of the year.

Wood logging residues can be chipped in the forest directly or at the energy plant. The two most common logging residue systems are chipping at the landing and trucking of chips to energy plants and deliveries of loose logging residues to customer. However, the choice of logging residue procurement system is largely determined by the customer's receiving facilities and fuel requirements. 
Residues are sometimes collected and made into bundles. Bundling is generally used to make long distance transport more efficient, however it has also been shown to increase the amount of useable biomass that can be recovered from a harvesting site. ${ }^{31}$

Systems for delivering loose or bundled logging residues require that the material is sent to an energy plant or terminal with access to crushing equipment. Deliveries of loose logging residues to the energy plant or terminal are competitive as long as the transport distance is not too far. Logging residues are a voluminous material to transport which results in low payloads on logging residue trucks and higher transport costs per km than for other systems.

\subsubsection{Stumps}

\section{Harvesting and storage}

Current stump harvesting methods involve the stumps being lifted vertically upwards by machines. Usually, the stumps are being split in the ground before lifted. They are then shaken to remove stones and dirt, before being stacked in small piles at the harvesting site. They are left at the site to be exposed to the weather, which helps remove additional dirt and sand. They are later collected and transported with forwarders to the landing at the road side, where they are stacked in piles and can dry while waiting for collection.

There are two common types of extraction methods, fork type and shear type. The fork type resembles a conventional excavator bucket, but instead of the bucket it has 3-7 long fingers where one finger often is longer than the others to facilitate splitting of the stump before it is lifted. The common design feature for a shear type harvester is a powerful frame with two ripper teeth that are placed under the stump to pull them out of the ground.

There is also another type of extraction method called root cutters, but there is currently only one unit with a practical application. This is the rotary stump cutter, which is currently only a prototype and has not yet been released onto the market.

\footnotetext{
31 Diploma work by Nilsson B., (2007) Pre-treatment of Biomass from Forest - Efficiency and costs of different pre-treatment systems of logging residuals outtake, Växjö University (Swedish).
} 


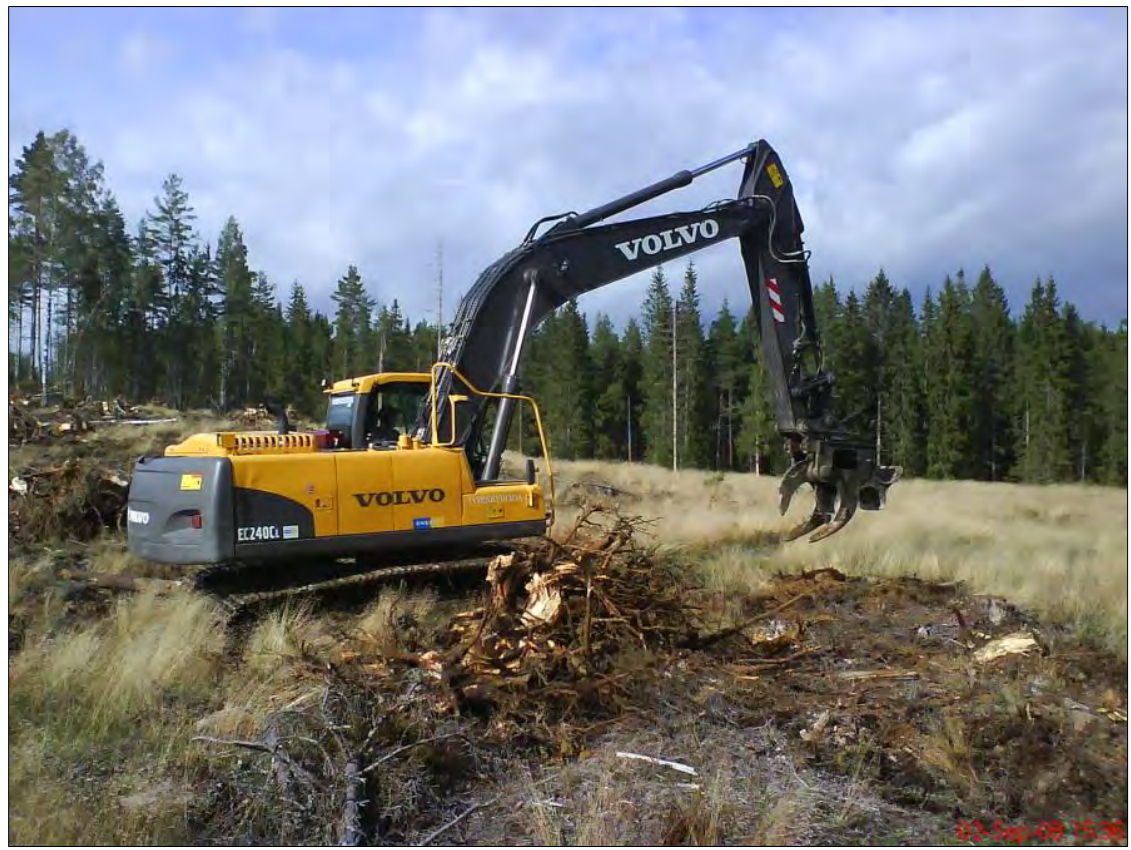

Stump parts are difficult to handle as they are bulky and contaminated by soil and stones. Although the stumps have been split on extraction from the clear cut, the stumps are irregular and difficult to load on trucks at the landing. One way of increasing the payload and reducing transport of contaminants is to coarse-grind the stumps directly on the landing. One of the main advantages of this is more efficient truck transport. Other advantages are decreased ash content in the delivered stump wood and increased thermal value. The ratio between input energy (diesel consumption of the machines) and the energy content of the stump wood is also improved. Calculated for the entire chain, from stump extraction on the clear cut to fuel at the terminal, the proportion of input energy in relation to the energy content in the delivered stump wood was 3,1\% for the coarse grinding system and $4,1 \%$ for the conventional system with grinding at the terminal/heating plant. ${ }^{32}$

\section{Effects on the ecosystem}

Removal of biological material is affecting the ecosystem. Harvesting logging residues causes nutrient losses to the forest ecosystem because tree's nutrient content is stored mainly in branches and especially in needles. This has negative effects on the fertility of the forest soil. Removing logging residues also causes indirectly some other effects on the

32 Thorsén Å., Björnheden R., Eliasson L., (Efficient forest fuel supply systems - Composite report from a four year R\&D program 2007-2010, Skogforsk. 
growth and ecological condition of the forest. It may change the micro climate and microbe activity, acidify soil and also slow down the mineralization of nitrogen in the humus layer. On the other, hand removing logging residues decreases leaching of minerals such as nitrogen 22$33 \%$ during the first few years after cutting.

Removing logging residues has effects also on soil acidification. During the growth of the tree crop natural acidification of the ground takes place when the positive ions such as $\mathrm{NH} 4+, \mathrm{Ca}+$ and $\mathrm{K}$ are bound to the growing stock. These ions will be released back to the ground after death of the tree via decomposing and that compensates the acidity. Removal of the logging residues has been observed to effect about $0.1 \mathrm{pH}$-unit on the acidity of the forest soil in the final felling stands. ${ }^{33}$

Combustion residues i.e. biomass ash is also recycled to the soil in order to compensate for the removal of mineral nutrients and to maintain the buffering capacity of the soil.

However, there is still relatively little information and research data on the leaching of the nutrients from the harvesting and storage areas. If there is a need to fertilize the forest because of the harvesting of energy wood, information is also needed on the leaching of fertilizers. This information would also help to effectively allocate the water protection programs.

\subsubsection{Biomass chips production}

The chipping of the wood used for energy purposes can take place both directly in the forest, at a terminal, or at the end user. For chipping at the harvesting site either mobile chippers or trucks equipped with chippers are used.

If chipping is performed at a terminal or at the end user, both mobile and stationary chippers can be used. Mobile chippers are normally hired for short periods to produce enough chips for a specific period of use, i.e. they will be used one day per week to produce enough chips for the rest of the week. This reduces investment cost for the end user.

There are various designs of mobile chippers, which vary according to the material used, volume to be chipped, and the desired product. For small capacities, chipping of forest residues, and mobility, i.e. to chip at the harvesting site, the most commonly used devices are small crushers of various designs. For larger capacities and for chipping roundwood, larger drum chippers and grinders are used. Grinders are used to produce a smaller particle size distribution, and for more contaminated

${ }^{33}$ Kallio et al, 2005. 
material. Chippers are used when the raw material contains more stem wood and when the particle size should be kept larger.

Due to the high investment and operation costs, stationary chippers are not often used in bioenergy plants. They are only justified when the raw material supply at the plant is expected to include a large amount of roundwood, and when the capacity of the energy plant is high.

The wood chips are normally transported directly to energy plants but in some cases they are stored in the forest, at the roadside or in the clearing.

If chips shall be stored for more than a few days, they should be of the best possible quality. In most cases, wood chips piles are placed outdoor, but if the moisture content needs to be reduced, or restricted from increasing, it is necessary to place the wood chips under a roof. Wood chips are a suitable growth medium for mould fungi and in a pile of wood chips with high moisture content the fungi grows very fast and soon the entire pile can be infected with mould fungi.

\section{Environmental impacts of crushing and chipping}

Crushing and chipping biomass are the most significant noise sources. Noise emissions caused by several different wood chipping and crushing machines have been measured. Measured sound pressure levels varied between 116-130 $\mathrm{dB}(\mathrm{A})$, when the main parts of the noise levels were around $120 \mathrm{~dB}(\mathrm{~A})$ or below. ${ }^{34}$ Also wheel loaders and trucks used for biomass loading and transportation create some noise.

\subsection{Handling, Natural drying and other processes at growing site - Cultivated biomass and agricultural residues}

\subsubsection{Fast growing energy forest (Willow)}

\section{Harvesting}

Harvesting takes place in the winter (between November and April), after growing period when, the leaves have fallen and the ground is frozen. Willow is harvested at intervals of 3-4 years and the yield can reach $7-10^{35}$ oven dried tonnes of willow chips per hectare and year, although the first harvesting is normally smaller. The life span of willow plantation is estimated to be more than 25 years. Willow can be harvested, cut and chipped directly on the fields or as whole shoots.

\footnotetext{
${ }^{34}$ Ruhanen, 2011

35 SOU (2007:36) Bioenergy from the agriculture - a growing resource, (Swedish).
} 


\section{Storage and transport}

Normally the willow chips are transported directly to heating plants after harvesting, primarily in bulk transport vehicles, but in some cases the chips are stored in a stack. There are a number of problems associated with the storage of willow chips in a stack. Freshly harvested chips stored in a stack break down faster, due to microbial activity. Willow can also be stored as whole shoots in a pile. The advantage with the storage of whole shoots is that the moisture content is reduced from around $50 \%$ to approximately 35\% between March and September, corresponding to lower losses, higher density of energy, and better quality of the fuel.

\subsubsection{Reed Canary Grass}

\section{Harvesting}

Harvesting primarily takes place in the spring when a dry product is received with a water content of around $10-15 \%$. The seeds are first harvested in the winter/spring two years after sowing and after that at the same time period year after year. The yield can reach 4-7 oven dried ton per hectare and year. The nutrients and elements that cause problems in the boiler have to a large extent leached out during the winter. Because of that, a small amount of nutrients are removed from the area during harvest.

A disadvantage with spring harvesting is that the feasible harvesting period is relatively short. There are two reasons for the restricted period. Firstly the ground has to be dry during harvest to minimize the risk for driving damage from harvesting vehicles, and secondly the harvesting must be done before new green shoots are established. The shoots can otherwise be damaged by the harvesting machinery, which will affect the next harvest yield in a negative way. Shoots may also contaminate the harvest, because of the high water content and the high amount of nutrients.

There are two common methods for seizing reed canary grass (for energy purposes) during harvesting and these methods result in rectangular bales and round bales. Shredding the grass in the field is an alternative harvesting method.

\section{Storage and transport}

Storage stockpiles of bales shall be covered. Since reed canary grass has low water content there is a relatively small risk for microbial activity during storage. Round bales withstand rain showers in the field better than rectangular bales. Reed canary grass is usually transported in bales because the density of reed canary grass chop is very low. When using 
rectangular bales rather than round bales, it is possible to make $30-50 \%$ heavier loads for transportation. Reed canary grass in bales is profitable to transport up to distance of $70-80 \mathrm{~km} .{ }^{36}$

\subsubsection{Hemp}

\section{Harvesting}

To make full use of the growing season hemp should be sown as early in the spring as is possible. Hemp for energy purposes is best harvested after the leaves have fallen off, which happens after the frost has set in. The nutrients in the leaves are not removed from the area during harvest and can benefit future crops. Frosts also cause the stems to dry and towards spring the steams become very dry (10 to $20 \%$ ). Hemp that is harvested in the spring can normally be brought in with low water content.

There are two methods for seizing hemp (for energy purposes) during harvesting: in one method, the hemp is pressed into rectangular or round bales, in the other method, loose material is chopped into small pieces. Baling offers an effective means to collect, handle and store the material, but it is also a significant cost item in the production chain. The hemps fiber can lead to problems during the harvest; the strong fibers can cause problems with screw feeds and other types of in-feed equipment where it is getting stuck and entangled.

If the hemp is harvested in the spring, the moisture content is very low and it is fragile and breaks up easily. A large quantity of small particles is formed and this dust is given off when handling loose stored hemp, which means that workers handling the material must ensure they use appropriate protective equipment to avoid inhaling it.

\section{Storage and transport}

Since the crop is only harvested once a year, often in spring when the need for raw material in heating and power plant is low, storage of the harvested material is often required. Bales can be stored indoors or in a covered pile to protect them from rain. Loose material can be stored in covered silos or in tubes. As with other straw material, it is also important to be able to compress hemp to keep down storage and transport costs. 


\subsubsection{Straw}

\section{Harvesting}

When the grain fields are harvested, the straw is left in swaths. The farmer will normally be interested in having the straw removed as soon as possible to be able to start preparing the soil for the following year's crop. When harvesting straw, a baler machine is used and there are two common technologies used when harvesting straw for energy: rectangular bales and round bales. Shredding the straw in the field is an alternative harvesting method, e.g. when straw is used as a raw material for pellets or briquettes. However, the low density and relatively complicated handling make storage and long transport expensive.

There are numerous of different sizes of bales. The average dimensions of "big rectangular bales", which are the most common bales, are $240 \mathrm{~cm} \times 102 \mathrm{~cm} \times 130 \mathrm{~cm}(\mathrm{~L} \mathrm{x} \mathrm{W} \mathrm{x} \mathrm{H).} \mathrm{The} \mathrm{average} \mathrm{weight} \mathrm{will} \mathrm{vary} \mathrm{but}$ typically, a bale could weigh 550-650 kg. There has been some interest in producing bales at a height of $90-100 \mathrm{~cm}$, instead of $130 \mathrm{~cm}$, due to better utilization of truck capacity can be obtained. By having 3 layers of 90-100 cm bales instead of 2 layers of $130 \mathrm{~cm}$ bales, the average weight of a truck load can be increased by $40-50 \%$. Almost all straw for large scale combustion in Denmark and Sweden is produced and handled as "big rectangular bales".

\section{Storage}

Straw bales should be transported from field to storage as soon as possible after pressing. If it rains on the bales after pressing, water will penetrate the bales to different depths depending on the type of bales.

Figure 10. Straw bales wrapped in plastic stored outside in the field

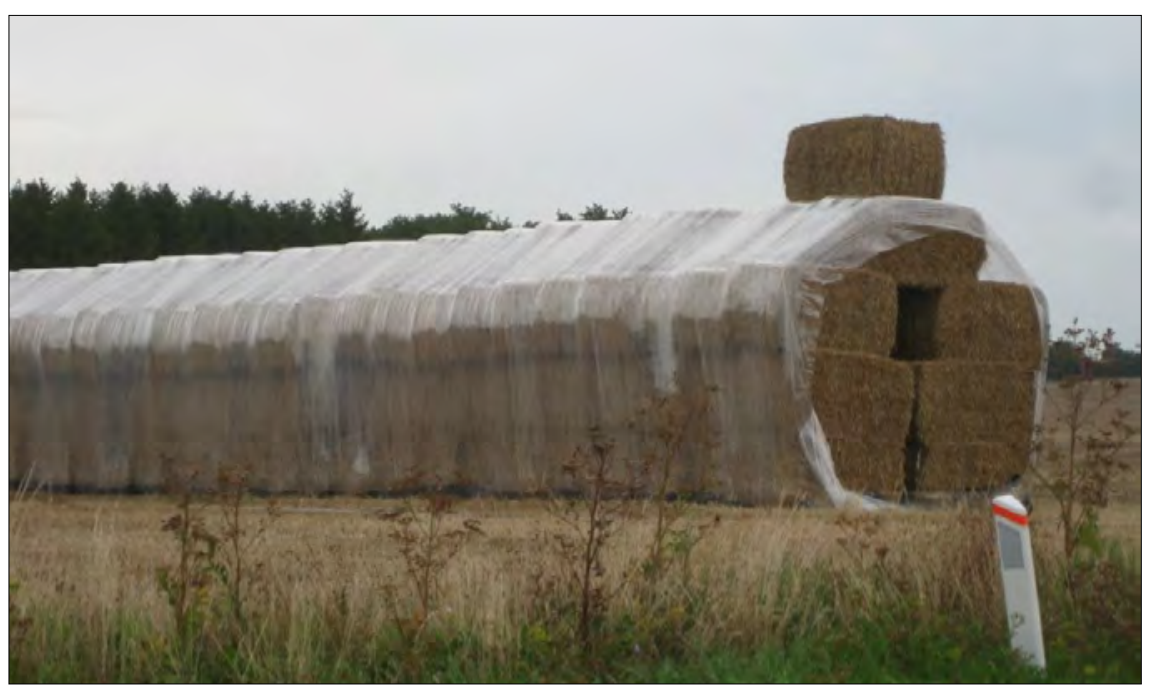


During storage, there are losses that are caused by microbial activity because the autumn climate can make it difficult to harvest the straw with sufficiently low moisture content. In both Sweden and Denmark, where straw-fired heating plants are common, moisture content higher than $20 \%$ is usually not accepted.

Uncovered outside storage is by far the cheapest means of storage but the one with most risk attached. Round bales are most tolerant with outdoor storage and more resistant to rain compared with rectangular bales that are sensitive to rain and should therefore be brought undercover as soon as possible after harvesting. There is a machine on the market that can sheet over two rectangular bales on top of each other laid in a long string, called a tube liner. The bales are lifted onto a platform with a front loader and then wrapped in plastic to form a long sausage as more are added. Bales that can be wrapped in this way can have a water content of $\max 14 \%$.

\section{Transport of straw}

The straw bales can be transported from storage to the energy plant by either tractor trail or by truck. However, tractor trail should only be used with rather short distances between storage and energy plant.

As straw has a relatively low calorific value based on volume and weight, the price of straw is sensitive to the distance to the power plant, which results in regional price differentials for straw.

Transport cost reductions can be achieved through increasing volume densities, co-handling with other fuels and minimizing steps in the chain.

\subsubsection{Grain and grain stalks}

\section{Storage and transport}

As grains have been, and still are, a very important farming product, there is a well developed and thought out logistics system for them.

\section{Environmental impacts of handling cultivated biomass and agricultural residues at growing site}

Previous chapter 4.1, effects on the ecosystem of forest harvesting, is also applicable for cultivated biomass and agricultural residues. Environmental aspects of handling energy crops and agricultural residues are in many cases similar to traditional agriculture. There are dust problems associated with harvesting and storage of these kinds of biomasses.

Freshly harvested willow chips stored in a stack break down fast due to microbial activity. Reed canary grass on the other hand has low water content why it is a relatively small risk for microbial activity during storage. If hemp is harvested in the spring, the moisture content is very low and it is fragile and breaks up easily. A large quantity of small parti- 
cles is formed and this dust is given off when handling loose stored hemp, which means that workers handling the material must ensure they use appropriate protective equipment to avoid inhaling it.

\subsection{Transportation}

Biomass can be transported by road, railway or sea, which results in different costs of transport. Transport by road is the most common way of transport at shorter distances. Longer distances often make transport by rail or sea the most cost effective option. However, it is important to point out that the cost of transport often is very dependent on local prerequisites and general transport costs are often difficult to present.

Chipper trucks combine chipping and chip transport. Chipper trucks with a switch-body system for chip containers have become more common in recent years. Compared with traditional chipper trucks, their advantages include better utilization of the chipper. The wood is chipped straight into containers which can be transported to the point of end use.

The major advantage with transport by railway is that it enables the transportation of biomass harvested from larger distances. In addition, railway transports result in less greenhouse gas emissions as compared with road transports. However, railway transports require terminals for loading and unloading both in sending and receiving sites.

The most important cost influencing factors in railway transports based on a calculation model have been observed to be the following: ${ }^{37}$

Calculation basis has been the number of deliveries that a train unit makes per a time unit (hour or day):

- Utilization of load capacity

- Transport distance

- Terminal handling

- Conditions for train shunting at terminal points

The fixed costs are high for railway transports and in order to reduce the proportion of the fixed costs, they must be spread over a large volume.

\section{Environmental impacts of transportation}

Environmental aspects concerning biomass transport are mainly related to transport efficiency and dusting/littering during transport. Transports should be planned so that the maximum load can be achieved in order to minimize the fuel consumption and $\mathrm{CO}_{2}$-emissions. Dusting and

\footnotetext{
37 Thorsén Å., Björnheden R., Eliasson L., (Efficient forest fuel supply systems - Composite report from a four year R\&D program 2007-2010, Skogforsk.
} 
littering during transport must be prevented for example by covering the load with appropriate means. This will also increase the traffic safety. Special transport equipment for stumps and forest residues has been developed including special solutions to decrease the dusting.

\subsection{Handling and storage at terminals and at the point of use}

\subsubsection{Biomass Logistics Terminals}

Biomass can be transported from various harvesting sites to terminal, which are located at a strategically selected site and have good logistics connections. For example that industrial waste heat could be used for fuel drying while having the fuel stored.

These biomass logistics terminals are sometimes used to handle, process and temporarily store fuel prior to delivery to the end point of use. A terminal might be established if the biomass growing sites are located far away from the end-point of use. In this case train, ship, or barge transport would be used to transport the fuel from the terminal to the final destination.

The handling and processing technologies and methods used at the terminals are often the same as those used at the harvesting sites or end points of use. Upon arrival the biomass is normally unloaded into temporary storage facilities to wait for the final transportation. Shipping containers can sometimes be used for the temporary storage. Sometimes the biomass may be placed into uncovered storage facilities. In these cases the location of the site and the restrictions regarding noise, dust and water emissions play an important part in this decision.

Pellet storage must always be covered to ensure the pellet quality is maintained and also to prevent the spread of dust around the site.

Mobile equipments are most often used for handling the biomass at terminals. These provide most flexibility for moving the biomass inside the terminals and also for unloading and loading the transport vessels. The exact choice of equipment should be based on the types of biomass to be handled and the transport vessels. In large terminals, i.e. those used for loading larger ships, more automated handling systems and equipment are used.

Some terminals are used also for biomass processing, like chipping and crushing of forest residues, stumps and logs. In these cases it is necessary to have chipping or crushing equipment located at the terminal. The choice between using mobile or permanently installed equipments will be based mainly on the long term prospects of the terminal. Permanent installations are used in terminals with long and high utilization rate providing that the investment analysis is justifiable. If the terminal 
is expected to be in use only for some months or few years, then mobile chipping and crushing equipments are preferable.

\section{Environmental impacts at biomass terminals}

Chipping and crushing are operations that generate high levels of noise emissions. Terminals located close to residential areas normally have restrictions regarding noise emissions. In these cases the possibilities to use mobile chippers and crushers outside is limited affecting the choice between mobile and permanently installed equipments.

\subsubsection{Biomass receiving}

\section{Weighing}

Biomass is most often delivered to the point of use by truck. The advantage of using trucks is that it allows delivery direct from the harvesting site without the need for unloading and reloading en route. However, the cost effectiveness of using trucks decreases after transport distances over 100 to $150 \mathrm{~km}$. Train transport is a more cost effective with longer distances, as much larger volumes of biomass can be transported with a single delivery.

The biomass deliveries are usually first weighed to measure the amount delivered. Samples should be taken frequently to check the quality of the fuel delivered and ensure that it confirms with the delivery contract requirements. The end-point-user often pays the biomass supplier based on the quality of the fuel. The quality requirements are specified in the fuel supply contract, i.e. energy and moisture content, particle size distribution or maximum dimensions, and content of impurities like metal and stones.

Modern truck weighbridge systems are operated by the truck driver without leaving the truck cab. An identifying code, card, or electronic key is used to identify the truck and type of biomass being delivered. Dynamic weighing, i.e. where the truck continues moving slowly over the weighbridge during the weighing process, has been used in some installations, however stationary weighing is still more common as it is easier to ensure the accuracy during weighing.

Train weighing systems are based on dynamic weighing. For train weighing RFID identification chips cards are mounted on each carriage. These contain information on what the wagon is carrying, who the supplier is, and the tare weight of the carriage. RFID reading sensors are placed next to the rail track and as the wagon passes over the scales the information in the RFID chip card is transferred to the weighing system database. 


\section{Receiving chipped and crushed biomass and pellets from trucks}

The emptying of trucks delivering already chipped or crushed biomass can be either performed at the rear or side of the truck.

Rear emptying of trucks is performed either by tipping the container, or by an in-built conveyor. Similar methods are used in side emptying.

Pellets are delivered either in containers or in self-unloading trucks. These trucks will use pressurized air to unload the pellets pneumatically into storage silos. If containers are used, the pellets are unloaded into receiving hoppers similar to that used for receiving chips.

Extra care must be taken with dust control and explosion protection when handling pellets due to their low moisture content and dusty nature. Pellets are easily damaged so they should always be stored indoors and should be protected from moisture in order to maintain their fuel quality.

Normally trucks are emptied directly into the receiving hopper. In small plants the receiving system may also act as a storage system, whereas in large plants the receiving system forms an intermediate between trucks and larger storage silos.

In cases where dust will not create a problem the receiving hopper can be installed outdoors without any walls or roof. However, it is recommended to cover the hopper to protect biomass from rain and snow ingress into the hopper. Dusty biomass should be emptied indoors to prevent the dust spreading around the plant and to reduce health and safety risks.

The size of the receiving system and the capacity and number of the hoppers must be calculated based on the amount of biomass used by the plant, the truck size and type and the time periods when deliveries are made.

To avoid the risk of bridging in the receiving hopper, the hopper geometry should preferably include vertical, or near vertical, walls. Concrete is most widely used for hopper wall construction; however steel can also be used. In wintertime the cause for bridging can be icy biomass and snow with it. In some of those cases fuel silo walls can be equipped with electrical heating systems to avoid bridging. 
Figure 11. One type of receiving pocket fitted with chain reclaimer and used for rear unloading trucks

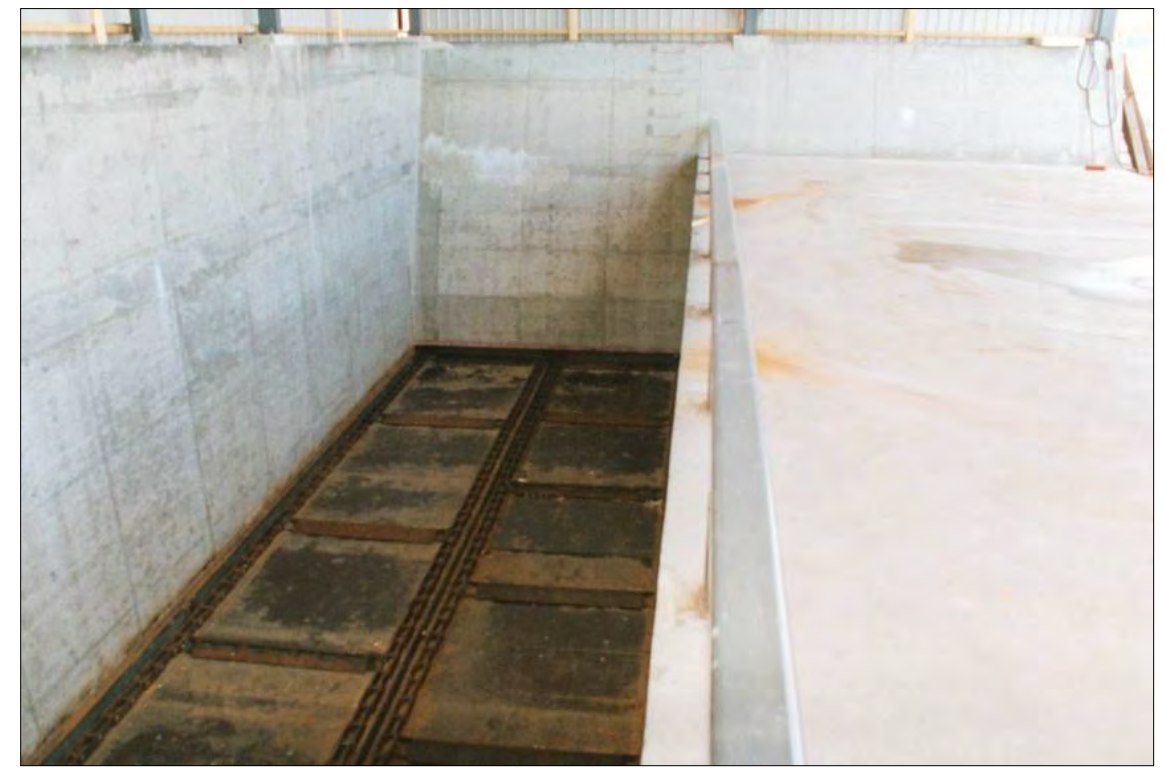

The reclaiming equipment used inside the hoppers will depend on the hopper size, the biomass handled, and the capacity needed. Where only chips will be handled, screw-type devices can be used. Where the biomass includes forest residues and bark, it is recommended to use either chain reclaimers or hydraulic stokers. In recent years chain reclaimers have been most popular due to the lower investment cost as compared to hydraulic stokers.

\section{Figure 12. One example of a levelling roll arrangement in a chip receiving hopper}

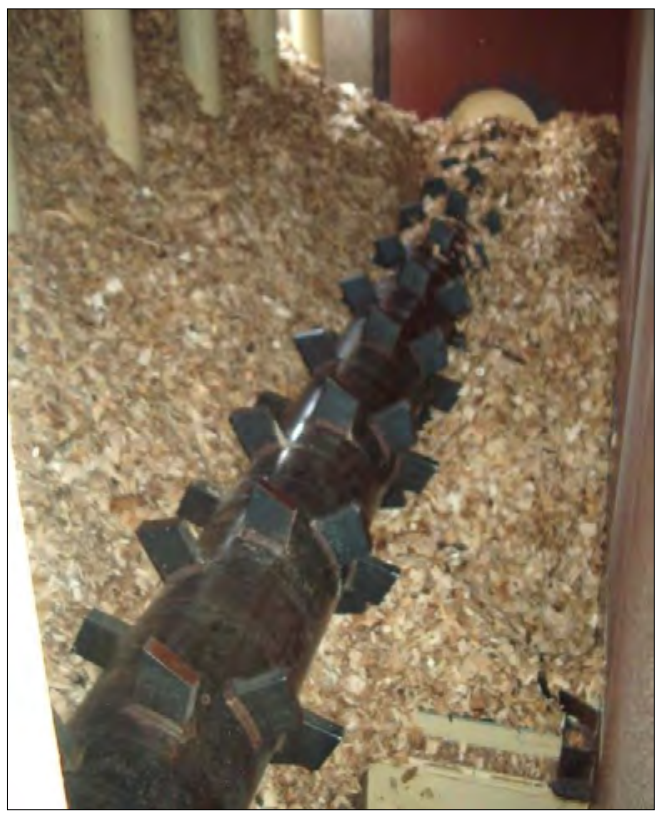


Leveling rolls, or breaker rolls, should be installed at the discharge end of the hopper to control the flow of material from the hopper into the next conveyor, and to help break up of frozen lumps in the material.

\section{Receiving chipped and crushed biomass and pellets from trains}

Train wagons used for carrying chips and crushed biomass are normally designed for unloading at the side. Unloading can be achieved by tipping the wagon or by using front-end loaders to unload the biomass and transfer it to receiving hoppers. Alternatively containers are used and are lifted off the train by mobile equipment before being unloaded by tipping.

If pellets are delivered by train they can also be in containers that are lifted off the train for emptying. Alternatively wagons designed for bottom unloading can be used.

The equipment and processes used for receiving and handling the biomass and pellets are the same as when receiving from trucks. Similarly, the same environmental and safety issues apply and should be controlled in the same way.

\section{Receiving logs, chipped and crushed biomass, and pellets from ships}

When biomass needs to be transported for long distances, or between countries, ships or barges are often used. Biomass is transported in many different sizes of vessels, from barges carrying a few thousand ton to Panamax vessels carrying fifty-thousand ton or more.

Loading of crushed and chipped biomass and pellets into ships and barges is carried out using various types of conveyors, but most often belt conveyors. Loading and unloading of logs is carried out using pier mounted cranes and mobile excavators equipped with special log grabs.

Unloading of the crushed and chipped biomass and pellets is performed by various means. Some vessels are self-unloading and have a built in conveyor systems that can transfer the biomass to receiving hoppers located on the pier. Other vessels without self-unloading systems are most commonly unloaded using pier mounted harbor cranes fitted with large bucket grabs. Sometimes large mobile excavators equipped with bucket grabs are located on the pier and used for unloading smaller ships and barges.

Self unloading ships can more easily control dust emissions and spillages when compared to the use of cranes and excavators. Receiving hoppers should preferably be equipped with dust collection devices to minimize dust emissions. 


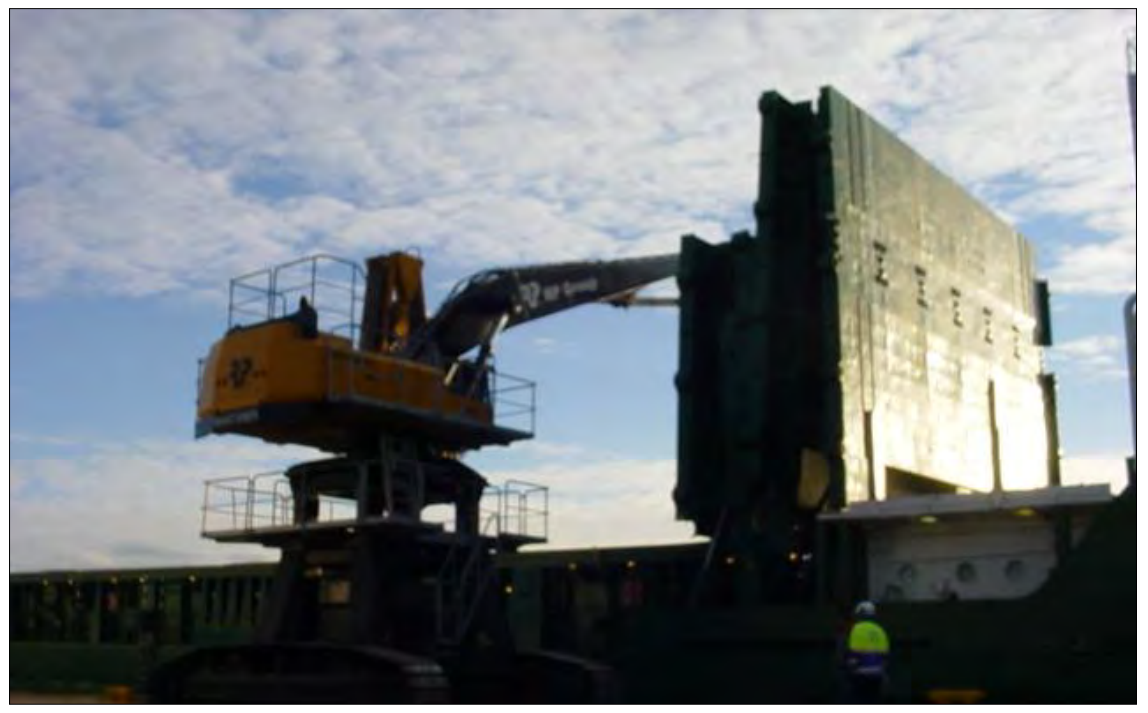

A very important safety issue in unloading crushed and chipped biomass and biomass pellets from ships concerns the risk of personal injury or death from entering confined spaces where there is a lack of oxygen and high levels of poisonous gases. There have been several deaths from carbon monoxide poisoning in cargo holds during biomass unloading. During transport, which sometimes can last several weeks, natural biological activity in the biomass causes a build-up of dangerous gases in the cargo holds. Therefore it is critical that the cargo holds are properly ventilated and measurements of carbon monoxide and oxygen levels taken prior to anyone entering the holds for unloading or cleaning operations.

The unloaded biomass is placed in hoppers on the pier from where it is conveyed further with belt conveyors. Pellets should be placed directly into covered storage; however crushed and chipped biomass should be first screened to remove oversize pieces and impurities. When planning ship receiving systems for biomass it is important to allow enough storage capacity so that the ships can be unloaded quickly and do not need to spend excessive amounts of time in port, which is expensive and increases fuel costs. Further handling of the biomass is similar to the methods used at the end user facilities.

\section{Receiving of logs and biomass that needs crushing or chipping}

When logs, or biomass that needs chipping or crushing, is received they are either unloaded directly into the crushing or chipping systems, or placed into outdoor storage.

Some biomass, like branches and stumps, can be delivered in containers or self-emptying trucks designed for unloading at the rear. In this case these trucks can unload directly onto a special receiving deck fitted with a conveyor that will meter the flow into a crusher feed conveyor, or 
directly into the crusher. These types of receiving decks are designed so that the truck can reverse onto the deck for unloading.

Trucks fitted with cranes can unload themselves, but otherwise mobile or stationary cranes are used. Often rubber wheel front-end loaders fitted with special grabs designed for lifting logs or loose biomass are used. Wheeled excavators fitted with similar grabs are also used when greater lifting height or reach is required. Stationary knuckle-boom cranes can be used however they are quite expensive and therefore can only be justified when the volumes of fuel to be handled is high.

\section{Chipping and crushing of logs and larger biomass pieces}

Logs used for biomass production are normally chipped with the bark still on the log. The logs are metered onto a chipper feed conveyor line, which can be a belt or chain conveyor, where they will pass through one or more stone traps and a metal detector before reaching the chipper.

The loading of logs onto the log deck and the further conveying of logs into the process will produce quite high noise levels. Therefore care should be taken in planning the layout and equipment design in order to limit the noise levels at sensitive areas.

The lifetime chipper knifes and wear-parts is very much affected by impurities such as stones and metal, and serious damage may occur to the chipper if metal passes into it. Therefore the use of metal detectors is very important.

It is also critical to note that there must be well designed safety systems. Strict safety procedures must be established in the removing process of biomass from the chipper and crusher feed conveyors as it sometimes requires the operator to enter the feeding conveyor while the chipper or crusher is still running. Any mistakes or accidents while the operator is on the feeding conveyor can easily result in fatal injury.

The main points when selecting the chipper design should be production capacity, the size of logs to be chipped, investment and operating costs and safety of the design.

When crushing larger biomass pieces like stumps and branches, there are two main alternatives. Since the early 1990's the most commonly used type of crusher for this bulky biomass is a large, vertically fed and slowly rotating crusher. The rotation speed is normally in the range of 30 to $100 \mathrm{rpm}$ and the capacity ranges to about 200 loose $\mathrm{m}^{3} / \mathrm{h}$. The investment and maintenance costs for this type of crusher are quite high. The annual production capacity is therefore an important factor in determining whether or not such an investment is justified.

Biomass crushers used in modern applications are less sensitive to metal and stones when compared to chippers. Small metal pieces will cause only minor damage and wear. However, larger pieces can still cause major damage to the crusher. Therefore the use of metal detectors is recommended in order to prevent large metal pieces entering the crusher. 
From the late 1990's several suppliers have developed large, horizontally-fed, biomass shredders designed for handling bulky biomass like branches, stumps, and even bundles of biomass. For these types of crushers the rotation speed is in the range of 500 to $1,000 \mathrm{rpm}$ and capacities range is to about 400 loose $\mathrm{m}^{3} / \mathrm{h}$. As these crushers operate at a much higher speed than the slow speed crushers, it is more important to prevent large metal pieces entering the crusher. There is also a higher risk of creating sparks which may cause explosions, so suitable protection methods should be adopted if the biomass is expected to have explosive properties.

\section{Biomass conveying to screening}

After receiving, crushing, or chipping, the biomass is transferred to screening. Several types of conveyors may be used The choice of conveyor type is mainly dependent on the layout of the plant, but also the type of biomass and the capacities needed play an important part.

In Nordic countries the most commonly used conveyor type is the socalled scraper chain conveyor. The main advantage of this conveyor is that it is dust tight and able to convey at steep inclines. In the handling of dusty fuels that can be explosive it is important to include explosion pressure relief doors on chain conveyors.

Belt conveyors are a more economical choice, especially when conveying distances are greater than about $50 \mathrm{~m}$. However, there are a disadvantages because of the fact that they require more space as their incline is more restricted. In order to prevent problems with biomass slipping back on the belt the maximum recommended incline in Nordic environments is 15 degrees and it is preferred to keep the incline below 12 degrees if possible.

Another disadvantage with belt conveyors is that they are not dust tight. In the handling of dusty biomass extra care must be taken to minimize dust cloud generation and to collect dust at the points where it is generated. This requires the use of self-cleaning dust collection cartridge filters, or similar. The dust is deposited back onto the conveyor so that it is conveyed further along the process. There have been some experiments with biomass dust suppression using atomized water mist sprays, also known as dry-fog technology. The use of this technology is not yet widespread in biomass handling systems.

It is important to consider the maximum lump size and impurities when selecting the conveyor type to be used between the receiving pockets and the screening system. Large frozen lumps or large stones $t$ may be present in the biomass flow.

Screw conveyors are not recommended for use between receiving and screening. Screw conveyors should only be used in this phase if the handled biomass is certain to be free of large lumps and impurities, the final quality fulfils boiler requirements. 


\section{Biomass screening and reject crushing}

It is recommended to always screen green biomass after it has been received as it is normal for oversize pieces to be present in the flow. It is also common for stones and metal to be present, in varying amounts depending on the type of biomass and where it has come from. Logs and whole tree chips can contain metal pieces embedded in the wood during the tree growth, i.e. nails, bullets, etc.

Screening systems in Nordic installations are normally located indoors to protect them from unfavorable weather conditions and also to minimize noise emissions. Commonly disc screen technology is used to remove oversized particles and reject them either to a crusher, or to a reject container.

Often a short belt conveyor is used to spread out the flow across the width of the screen, to provide bypassing of the screen and crusher, and also to allow a magnet to be used to remove metal pieces. If the conveyor between the receiving pocket and the screening system is a belt conveyor, it is possible to place the magnet at the discharge of this conveyor and dispense with the shorter belt conveyor. In this case a separate bypass chute should be provided to allow the screening system or just the crusher to be bypassed during maintenance.

Both self-cleaning belt magnets and non-self cleaning magnets may be used. The metal collected should be deposited and located into a container for recycling.

There are two alternatives for handling the screen rejects or oversize pieces. If the amount of rejects is expected to be small, it can be economically attractive to discard the rejects into a container to be treated either as waste or sold to another user with the ability to receive them. Alternatively the rejects can be collected and in case of large volumes be crushed by renting a suitable crusher for that purpose.

Where the amount of rejects is expected to be quite large, it is normal practice to process them directly with a crusher, and to feed them back into the biomass flow. There are many types of crushers that can be used to this purpose, ranging from high speed hammer mills to simple slow speed twin-rotor crushers. The slow speed crushers typically operate at about 20 to $50 \mathrm{rpm}$ and have capacities of to about 200 loose $\mathrm{m}^{3} / \mathrm{hr}$ depending on the material being crushed. The key differences between hammer mills and heavy-duty twin-rotor crushers are shown in Table 5. 
Table 5. Main differences between crusher designs

\begin{tabular}{|c|c|c|}
\hline & High-speed hammermill & $\begin{array}{l}\text { Heavy-duty twin-rotor } \\
\text { slow speed crusher }\end{array}$ \\
\hline Rotation speed & $>500 \mathrm{rpm}$ & $<100 \mathrm{rpm}$ \\
\hline Maximum lump size of product infeed & Approx. $<400 \mathrm{~mm}$ & Approx. <600mm \\
\hline Quality of fuel produced & Smaller size distribution & Larger size distribution \\
\hline Risk of explosions when handling dry dusty fuel & Medium & Low \\
\hline Risk of explosions when handling green biomass & Low & Low \\
\hline Maintenance costs & Medium to High & Medium \\
\hline Investment cost & Medium & High \\
\hline Investment cost vs. capacity & Low to Medium & Medium to High \\
\hline
\end{tabular}

\section{Biomass conveying to storage}

After screening and crushing the biomass should be conveyed to an intermediate storage. Similar selection criteria should be used as for the conveyors between receiving and screening. At this phase in the process the biomass properties are quite consistent and this allows the use of other types of conveyors such as screw conveyors, pipe-belt conveyors, and air-supported belt conveyors.

Pipe-belt conveyors are more expensive than normal belt conveyors and they can make turns, provided that the conveying route is long enough. This helps to eliminate the need for a transfer point and second conveyor in more complex layouts. Pipe-belt conveyors are also fully enclosed over the conveying distance leaving loading and discharge points open and enabling easier odor control.

Air-supported conveyors have become popular in recent years. These use a cushion of low pressure air to support the belt inside a steel pipe that is part of the conveyor gallery structural frame. This minimizes the need of moving parts such as idler rollers, and therefore also minimizes maintenance needs.

Where site space is limited, and a compact layout is necessary, beltbucket elevators may be used. Their design must be made carefully. Bucket elevators are more sensitive than other conveyors to the presence of impurities, large lumps, and variations in flow rate. Mistakes may lead to blockages and mechanical failure. The maintenance needs of bucket elevators are higher than for other conveyors and this should be considered when selecting the type of conveyor to be used.

The number of storage silos will directly affect the design of the conveyor system. When more than one silo is used, a distributing conveyor must be located over the silos to allow the flow to be directed to each silo.

When designing the layout of the conveyors and other plant items careful attention must be made to the need for maintenance access and providing platforms and stairs to allow this. The location and number of fire escape routes must also be considered. Regulations in each country dictate the maximum distances allowed between escape routes. It is recommended to avoid the use of spiral and helix staircases, even if they are not forbidden by regulations, as they make maintenance access more 
difficult and if there is an accident it can be impossible to carry a stretcher on the stairs.

\section{Storage and reclaiming of prepared biomass}

Fuel storing capacity at the point of use is important; a recommendation is to have storage for at least 2-3 days operation. In case of difficult traffic or bad weather conditions the transportation and fuel flow can be stopped.

In order to protect the fuel from unfavorable weather conditions it is preferred to store prepared biomass under a roof, so that the moisture content does not rise. Placing the biomass inside a silo provides the highest level of weather protection and also prevents dust emissions to the surrounding areas. The spreading of dust and chips is a significant problem in uncovered piles located in windy areas.

Two types of silo have been most commonly used in the Nordic countries for loose biomass. The most common is the circular silo equipped with a cantilevered radial screw reclaimer or similar. These are commonly used for storage capacities up to 10,000 loose $\mathrm{m}^{3}$ net, although most of the existing installations are below 5,000 loose $\mathrm{m}^{3}$ net. The other silo alternative used is the so-called "A-Frame" storage equipped with linear screw reclaimers or similar devices. A-Frame silos are often used where larger storage volumes are required. In some cases, due to layout restrictions, or due to the quality of the fuels handled, multiple circular silos will be used in preference to an A-Frame silo.

In modern installations circular silos are most commonly made from pre-fabricated flat concrete wall sections, similar to those used for large water tank construction. These are placed on top of a concrete base that may be constructed above or at ground level. The ratio of maximum fuel height to silo diameter has an important impact on the ability of the biomass to flow freely or bridge inside the silo.

On larger circular silos, approximately $\geq 22 \mathrm{~m}$ in diameter, a steel frame roof covered with insulated industrial roofing panels is fitted on top of the walls. In smaller silos a welded steel plate roof is often used. Access stairs should be provided to the top and centre of the roof so that the feeding conveyor and instrumentation devices can be maintained. Explosion pressure relief doors should be placed in the silo roof when the biomass is expected to have explosive properties. 


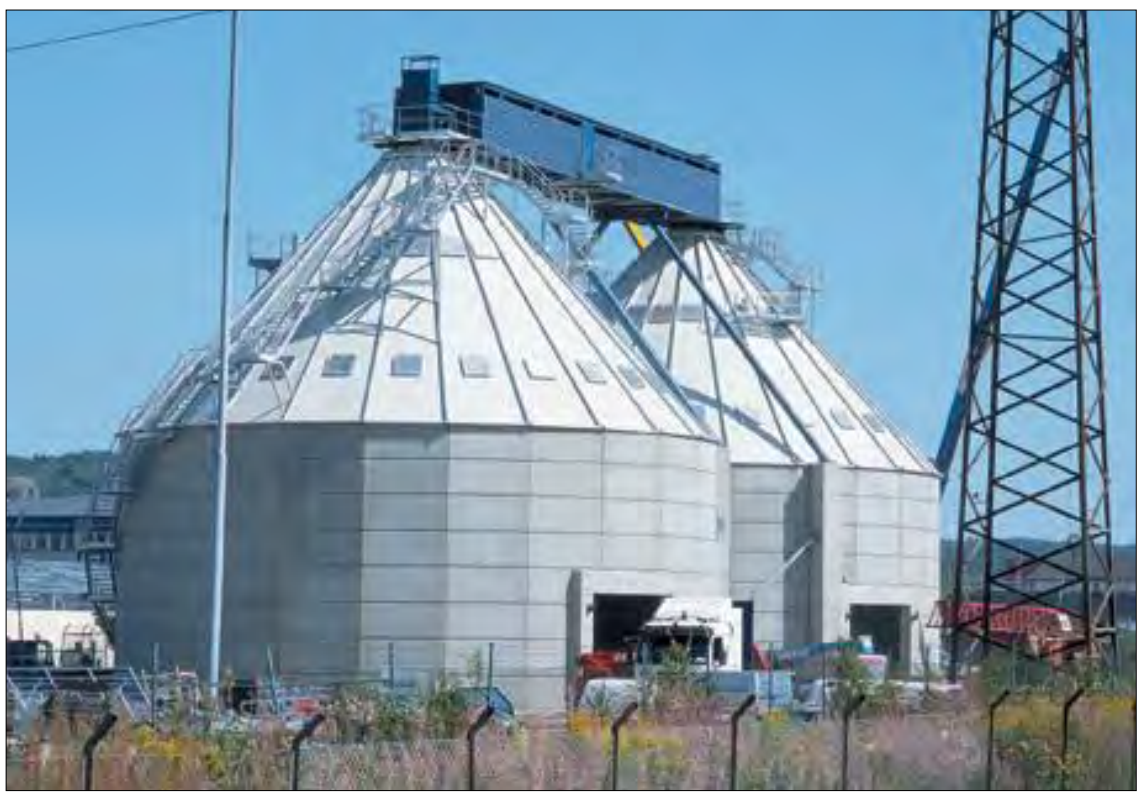

Source: Abetong AB

A-Frame silos have a concrete foundation upon which a steel frame roof is erected and covered with insulated industrial roofing panels. The floor of the silo can be located at ground level, but in that case the reclaim conveyor must be placed in a tunnel below ground level. If the silo floor is raised above ground level the need for tunnels can be avoided. The feeding conveyor from the screening system should transfer the fuel to the top and centre of the silo.

Inside the A-Frame silo a shuttle conveyor is located under the roof and is used to distribute the fuel along the length of the silo. Various silo arrangements are possible, and the layout can be chosen according to the site layout and capacities needed. The decision on whether or not to place the silo floor at ground level or raised above ground level should be made on a project-by-project basis as the local ground conditions and civil works costs have a big affect on this decision. 
Figure 15. A-Frame and circular silos for chip and bark storage at a pulp mill

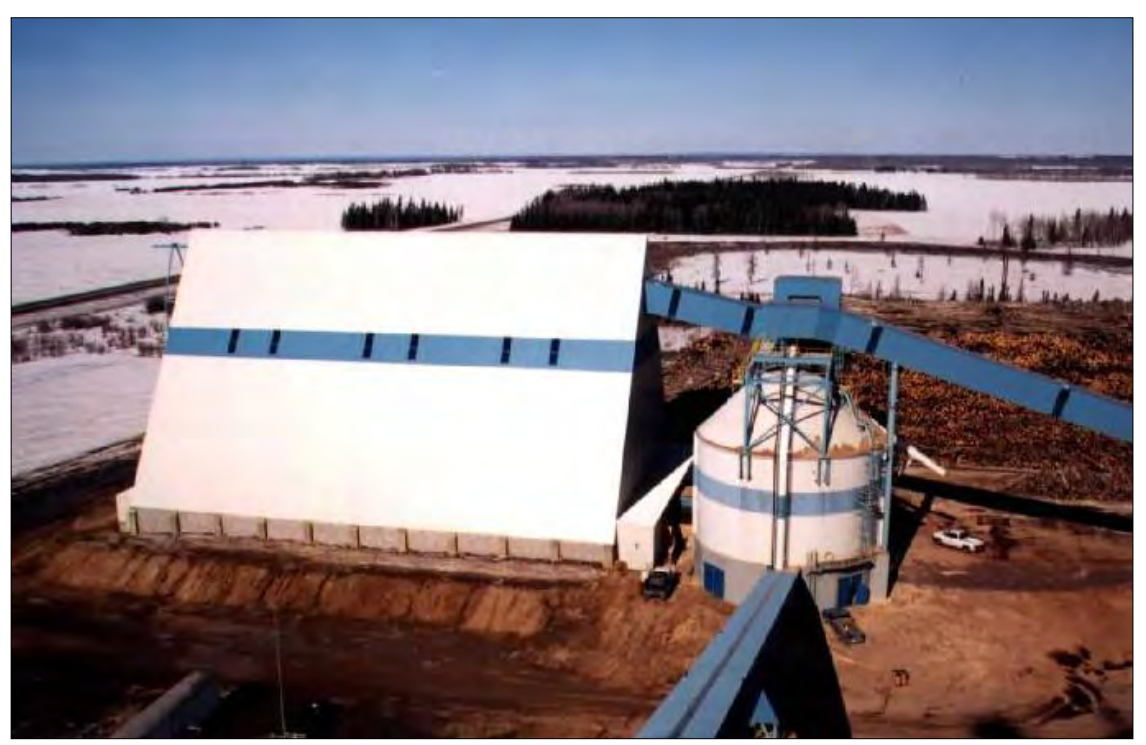

Source: Jeffrey Rader AB

Both A-Frame and circular silos should include a large access door that allows the fuel to be emptied with an excavator or front-end loader in the event of equipment breakage.

The reclaimer used inside circular and A-Frame silos is most often a screw reclaimer. Screw reclaimers are able to reclaim sticky and nonfree-flowing materials, so are preferred when forest residues and bark are handled. When quite good quality chips, sawdust, or similar freeflowing materials are handled, it is be possible to use other designs of reclaimers, such as the TubeFeeder ${ }^{\mathrm{TM}}$. It is important to select a reliable and well proven reclaimer design in order to minimize the risk of unexpected breakages and blockages. The operation of this equipment has a direct impact on the boiler availability, so a high level of reliability and up-time is required.

The reclaimer maintenance intervals differ greatly dependant on the fuels handled and the materials used for the equipment construction.

\section{Conveying to the boiler silo}

After storage the biomass should be conveyed to the boiler silo. Similar selection criteria should be used as for the conveyors between screening and storage.

If multiple silos are used, the conveyor system should be designed to mix the biomass from the different silos. Control of dust is again an important issue especially as the boiler transfer conveyor normally needs to rise high up into the air and any dust spillages can otherwise spread over a wide area. 


\section{Handling of straw at the plant}

At the small power plants, the straw is mostly unloaded with a fork-lift truck. At the larger plants, the unloading is carried out with a so-called overhead travelling crane. The crane is capable of unloading the bales from the truck as well as it also registers the weight of the straw and its moisture content. However, at small plants, the moisture content is registered with a spear which is manually pushed into each straw bale. Generally, the storage capacity of power plants is large enough for only a few days. 38

A great deal of dust is generated when breaking up and roughly chopping straw bale, which must be dealt with suitable ventilation equipment.

Figure 16. Example of straw handling at the plant

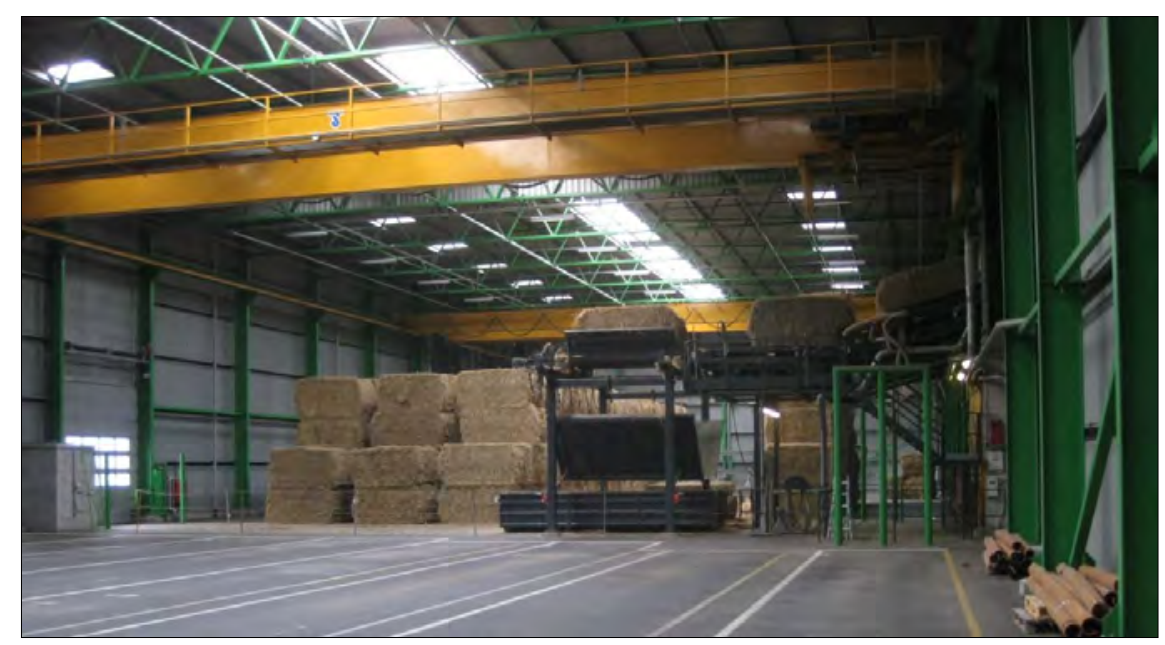

\section{Control of emissions to air and water}

Self-cleaning dust collection filters are used to capture dust generated during unloading and handling processes. The dust is returned to the main biomass flow in the conveyors. When unloading dusty biomasses drivers should be able to operate the system from a location where they are not exposed to the dust. For limiting dust emissions water dispersion systems can be used.

If biomass is placed into outdoor storage care must be taken with control of emissions to air and water. Chips and dusty materials can be easily blown around the site. These solids can easily pass into rainwater drainage systems where they should be collected in solids separators before the drainage water is released to any local bodies of water.

${ }^{38}$ Sander B. \& Skott T. (2007), Bioenergy for electricity and heat - experiences from biomass-fired CHP plants in Denmark, Dong Energy. 
Other harmful emissions like oil leakages can occur due to mechanical failure of the mobile equipment and trucks operating in the storage area. Therefore rainwater handling systems should also include oil separation devices.

Rubber wheel loaders and similar mobile equipment have high noise emission levels, in the range of $108 \mathrm{~dB}(\mathrm{~A})$, so their operating times are often restricted at sites close to residential areas. This should be considered when applying for permits, and also during layout planning of the plant.

Both chippers and high speed shredders emit high noise levels. Chippers can produce noise levels of approximately $110 \mathrm{~dB}(\mathrm{~A})$. It is therefore necessary to enclose chippers and crushers inside buildings designed to enclose and suppress the noise emissions. Care should be taken with the design of the feeding conveyors and how they enter the buildings to ensure noise emissions through these openings are limited. Slow speed crushers often use hydraulic drive systems and these can also be quite noisy, so care should be taken by placing the hydraulic power unit inside a noise enclosure, a room, or an underground area.

\subsection{Biomass dewatering and drying at industrial scale}

The fresh deforested trees have a moisture content of about $50 \%$. The moisture content is depending on the season, type of wood and part of the tree. There are several means of reducing the moisture content by natural drying (see chapter 4.1).

In different production processes there is, however, a need to dry the material by active heat transfer. This is the case for saw mill products and pellets (in most cases) as described in section 5.1.3.

For plants with only district heating purpose there is normally no economical or technical interest in drying wet biomass before the intake (some cases exist, preferable where waste heat can be used).

In the pulp industry debarking of the stem wood is done at the mill and the bark is used as a fuel for the heat production. In the cold winter period with freezing conditions a thawing of the stem wood with steam is leading to significant increase in moisture content. This will of course aggravate the combustion. A common technique to reduce moisture content is wet pressing (mechanical), after a crushing, where the moisture content is reduced to below $60 \%$.

At the same mill a second drying step can be installed with an active heat drying. The technique can be of either bed, drum or stream drying methods, see 5.1.3. 


\subsection{Environmental aspects}

\section{Emission to air}

Volatile Organic Compounds, VOC, emissions can occur during storage and drying of biomass. Emission of monoterpenes from bark has been determined to be high immediately after building a pile of fresh bark but declined within few days to acceptable levels. In the drying process of bark emission of terpenes, alcohols, fatty acids and resin acids have been detected. Laboratory tests have shown that during drying of forest chips and sawdust VOC compounds that will release are terpenes, alcohols, aldehydes and carboxylic acid. Emissions of aldehydes and terpenes have also been found in bulk storages of wood pellets. Typical compounds are hexanal, pentanal and monoterpenes.

\section{Dust emissions}

There is always some dust present when handling especially dry fuels produced from biomass. Dust is primarily an occupational health risk to the plant's employees. The operation of the plant should be organized in such a way that dust emissions are not spread to the surrounding air.

\section{Noise emissions}

Crushing and chipping biomass are the most significant noise sources. Noise emissions caused by several different wood chipping and crushing machines have been measured. Measured sound pressure levels varied between 116-130 $\mathrm{dB}(\mathrm{A})$, when the main part of the noise levels were around $120 \mathrm{~dB}(\mathrm{~A})$ or below. ${ }^{39}$ Also wheel loaders and trucks used for biomass loading and transportation create noise emissions

\section{Emissions to water}

Leachages from biomass outdoor storages can lead to solid organic and dissolved organic emissions into watercourse. Toxicity of leachates of pulp mill bark, saw mill residues and chipped residues from forest loggings in the laboratory scale has been examined with toxicity test. According to the results leachates from bark and saw mill residues were acutely toxic to the test organism Daphnia magna. The toxicity increased with time to a certain extent. The toxicity was caused partly by phenolic compounds. Leachates of the chipped logging residues showed no toxicity. 40

\footnotetext{
39 Ruhanen, 2011.
}

40 Håkansson, 2005. 
In laboratory storage tests carried out by lysimeters the quality of leachates from forest chips piles (green and brown) and fresh sawdust piles were determined. The test results showed that COD of the leachates varied between 2,000-9,000 mg/l, TOC 900-1,400 mg/l and $\mathrm{pH}$ 4-5.6. Total COD concentration of the leachates was $0.1-0.5$ weight- $\%$ and TOC $0.1-0.2$ weight- $\%$ of dry weight of the material. Highest amount of organic material was dissolved from green wood chips $(0.5$ percentage of weight). 



\section{The pellet and briquette production}

\subsection{The pellet production process}

This section gives a brief description of the commonly used processes for manufacturing of upgraded biofuels i.e. pellets and briquettes from biomass in Nordic countries based on existing information.

The pellet production process is dependent on the type of raw material that is processed and the location of the mill. It may be a stand-alone mill or integrated with e.g. a saw-mill or energy production plant. In general the major production steps in pellet production consist of (Figure 17):

1. Crushing

2. Drying

3. Pelletizing

4. Cooling and Sieving

5. Packing

Figure 17. General flow in a pellet production process

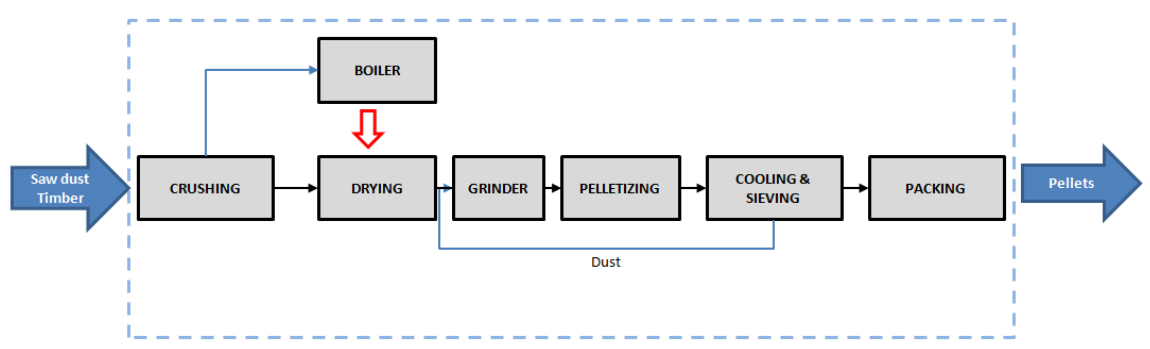

In the design of a production plant for pellets there are some questions and choices to be clarified.

1. Which type of raw material shall be used?

2. What type of crushing is needed?

3. If drying is needed which is the normal case which alternative cooperation's are to be considered (saw mill drying, available low grade or waste heat, district heating system, available steam system)

4. The drying technology is then chosen (see 5.1.3) 
The main processes or process steps with environmental effects are:

1. Transport into, at and out of the mill; emissions, noise

2. Raw material on the storage area; PM

3. Crushing; PM, noise

4. Drying with Heat generation; PM, NOx, SOx, VOC

5. In case of Condensation; dirty condensate

6. Grinding-Pelletizing-Cooling-Sieving; PM, noise, VOC

7. Packing; PM

PM $($ particulate matter $)=$ Dust emissions

VOC $=$ Volatile organic compounds emissions

\subsubsection{Plant information}

\section{Data sources}

Existing data from six pellet producers in Sweden has been collected. The producers are [with raw material/drying technique]:

1. SCA Bionorr, Härnösand [sawdust/stream dryer, FGC]

2. HMAB, Sveg [sawdust/steam dryer]

3. Derome Bioenergi, Veddinge [sawmill prod./bed+drum dryer FGC]

4. Rindi Västerdala, Vansbro [sawmill prod./bed+drum dryer, FGC]

5. Stora Enso Timber, Gruvön [sawmill prod./bed dryer]

6. Neova, Vaggeryd [sawmill prod./drum dryer, FGC]

\section{General data}

In Table 6 some general information of the producers is shown.

\section{Table 6. General data for the different producer}

\begin{tabular}{llrr}
\hline Producer & Reviewing level & Production(tonnes) \\
\cline { 3 - 4 } & & $\mathbf{2 0 1 0}$ & Permit \\
\hline 1. SCA Bionorr & Permission & $157,612 \mathrm{t}$ & $160,000 \mathrm{t}$ \\
2. HMAB & Notification & $108,090 \mathrm{t}$ & $330,000 \mathrm{t}$ \\
3. Derome Bioenergi & Notification & - & $50,000 \mathrm{t}$ \\
4. Rindi Västerdala & Notification & $48,000 \mathrm{t}$ & - \\
5. Stora Enso Timber & Notification & - & $100,000 \mathrm{t}$ \\
6. Neova & Permission & $114,006 \mathrm{t}$ & $200,000 \mathrm{t}$ \\
\hline
\end{tabular}

\subsubsection{Crushing (splitting)}

The raw material is crushed to reduce and homogenate the size. The type of crushing equipment is dependent on the type raw material. The types of equipment used are: 
1. Chippers (timber intake)

2. Flakers

3. Hammer mill

\subsubsection{Drying}

The drying process is the second most critical phase for the production economy since a considerable amount of energy is needed (the first is the raw material intake).

During drying part of the water volume shall be evaporated so the bio material reaches a moisture content of approx. 10\%. For the drying of a material with an initial moisture content of $50 \%$ and assuming $15 \%$ heat losses there is a need of an energy volume $0,95 \mathrm{MWh}$ per ton evaporated water.

A great part of this heat energy is present as water vapor (or steam in a steam dryer). By installing condensation equipment for this water vapor most of this latent heat energy can be recovered. The extent to which this heat energy can be recovered is very depending on the condition of the vapor and at which temperature it condenses. For the case with a steam dryer the latent heat is present as dirty steam but is fully condensable.

The latent heat recovered in the condensation could be sold as district heating. Another alternative is to use this low grade heat in a predryer. The dryer then consists of two steps where the second step uses the primary heat and the first step uses the recovered heat.

With a condensation step there will be a valuable cleaning effect for the dust outlet, but on the other hand it creates a need for condensate handling. This has to be considered when designing the dryer system.

The drying process is mostly continuous and several types exist: 41

\section{Drum/rotary dryer}

A drum or rotary dryer is a flue gas dryer with heat from a burner/furnace. The dryer is nearly horizontal with open ends and heated directly by the temperature limited (fire risk) flue gases and sometimes combined with indirect heating. Because to its uncomplicated design, this kind of drum is the dominating type of dryer in pellet mills.

${ }^{41}$ Roland Wimmerstedt, Björn Linde; “Analys av det tekniska och ekonomiska läget för torkning av biobränslen"; Värmeforsk rapport nr. 646. 


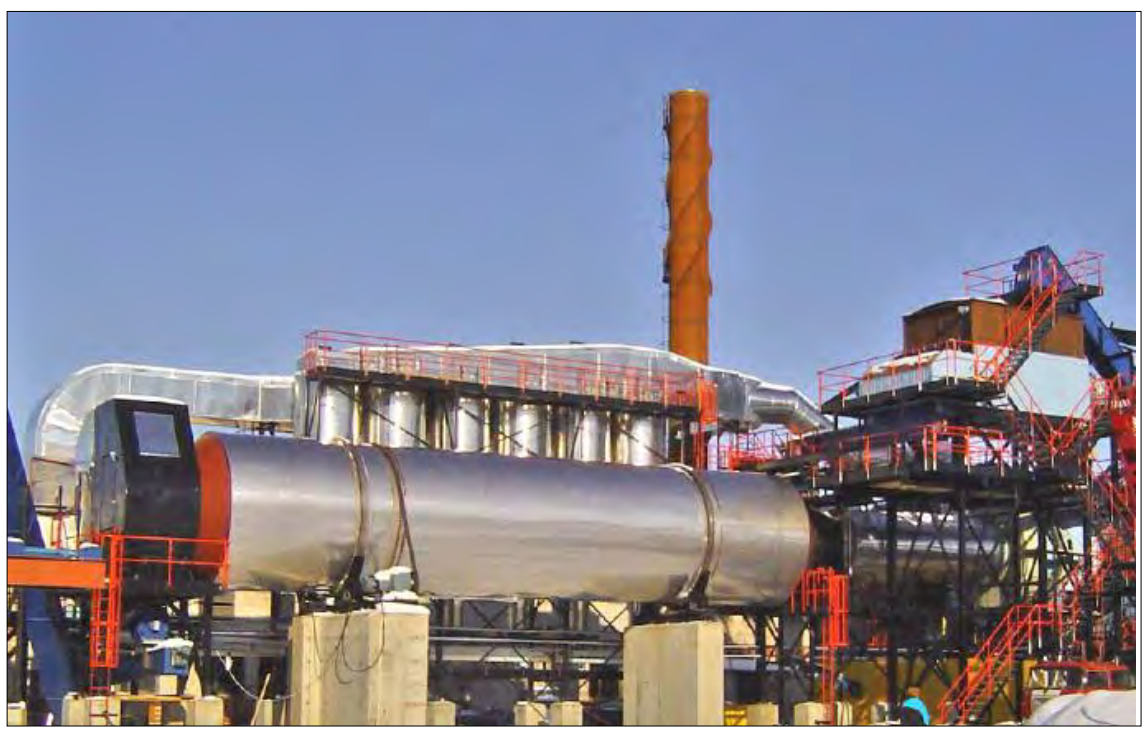

\section{Stream dryer/Flue gas dryer}

In a stream dryer the raw material is also dried directly with flue gases. At the same time the fan for the flue gases also is used for the pneumatic transport of the material. The dried material is separated in a cyclone and collected before feeding to the pellet machines. An example of the principal design is shown in Figure 19. The largest Swedish producer of pellets, SCA Bionorr in Härnösand, uses this technology in combination with a flue gas condensation plant connected to the district heating system.

Figure 19 Stream dryer, principle flow diagram

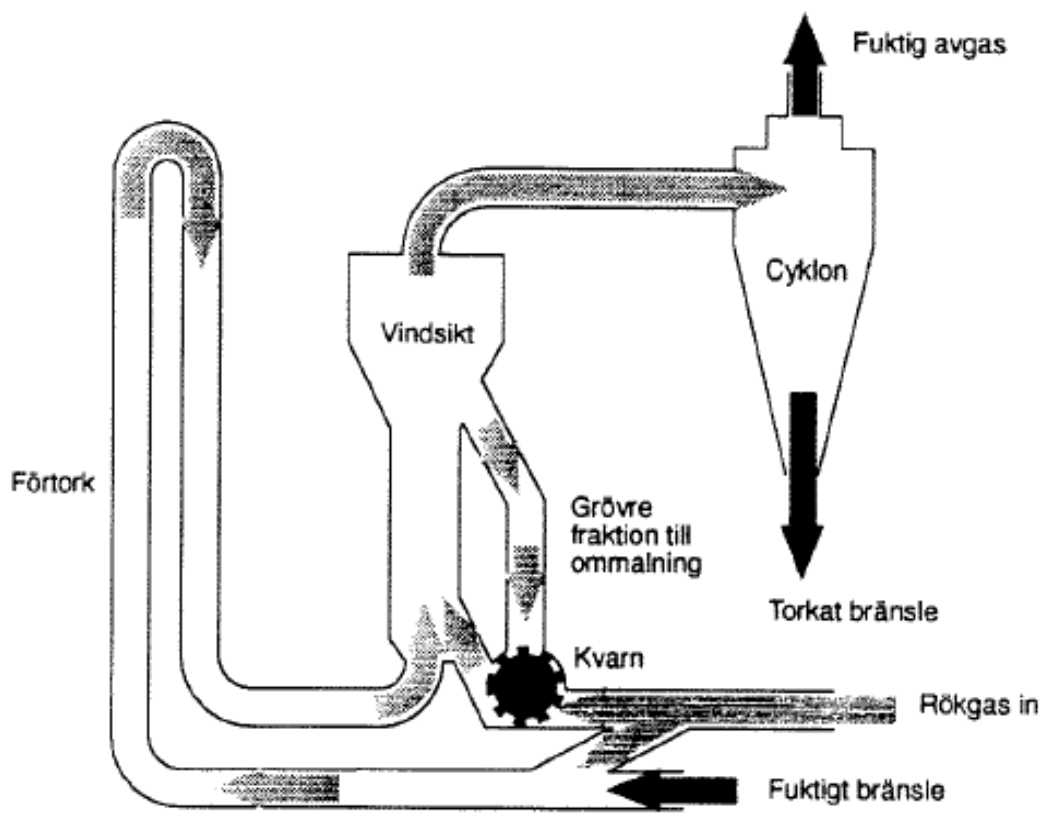




\section{Steam dryer}

A steam dryer uses steam from a boiler to heat a circuit with raw material and its evaporated water (as steam), see the Figure 20. The heating is indirect and the live steam is not in contact with the biomaterial. The drying circuit is closed and operated at overpressure (e.g. 4 bar), input and output of the material is therefore more critical compared to atmospheric drying processes. Most of the energy in the evaporated water (as dirty steam) can be recovered by condensation to generate hot water (or be used as low pressure steam).

\section{Figure 20 Exergy Steam dryer, principle flow diagram}

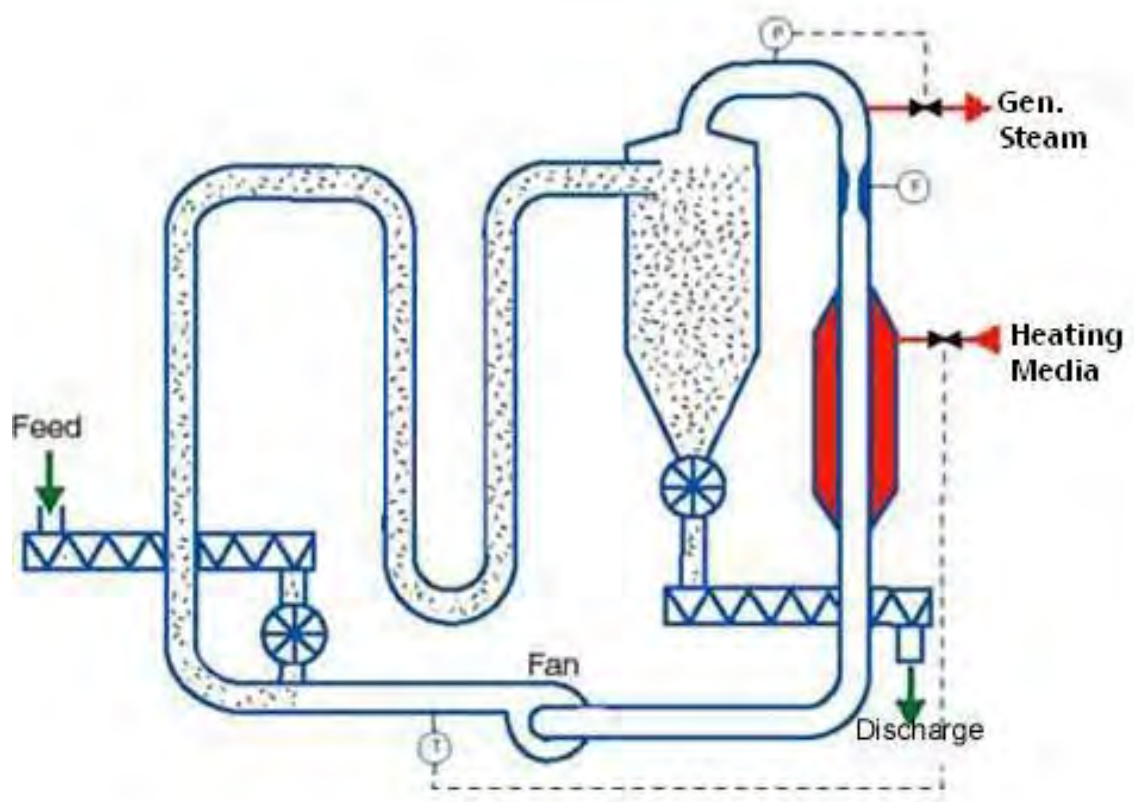

Source Swedish Exergy AB

\section{Bed dryer}

A bed dryer is an air dryer which can use low grade heat (above $70^{\circ} \mathrm{C}$ ). The bed dryer is suitable for recovered heat from condensation or for waste heat e.g. from a process industry. In a bed dryer the material is fed onto a horizontal perforated metallic conveyor belt (metallic or plastic). Heated air is pressed through the bed of material and through the belt. The specific energy is in the range between $1.05-1.35 \mathrm{MWh} /$ ton water evaporated, where the efficiency is falling with reduced temperature. Figure 21 shows a layout of a bed dryer (also called band dryer). 


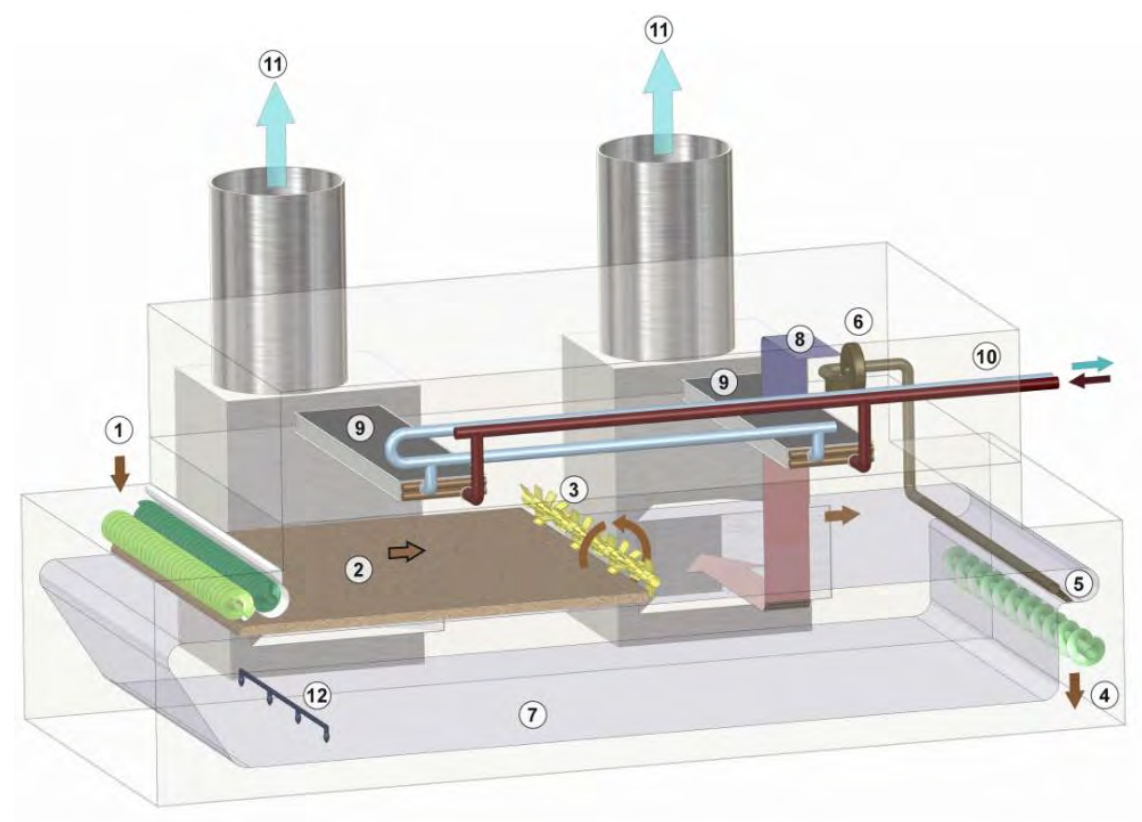

The Stora Enso pellet mill Gruvön is an example with an implementation of this technology with waste heat from the pulp mill. Furthermore the technology is used as the first step (of two) in the pellet mills in Vansbro and Kinnared (both in Sweden) where the second steps have drum dryers from which FGC:s recover heat to the bed dryers $(0.7 \mathrm{MWh} / \mathrm{t})$. The world's biggest pellet plant (2011) is Vyborg located in the Leningrad region in Russia near the Finnish border has four bed dryers. The production capacity is more than $900,000 \mathrm{t} / \mathrm{yr}$.

\subsubsection{Grinding}

The material from the dryers is typically conveyed to hammer mills. The bulk of the wood from the post dryer hammer mills is often separated from the air streams using cyclones. The separated, dried and sized wood is then usually stored in process storage bins prior to being fed to the pelletizes.

Reported values for the specific electricity consumption are 200-220 $\mathrm{kWh} /$ tonne.

\subsubsection{Pelletizing}

Pellets are produced by pressing the dried raw material (e.g. saw dust) through a steel matrix. The standard sizes of the holes in the matrix are 6 or $8 \mathrm{~mm}$, which give the diameter to the pellets. During the pressing some producers add steam and/or binders (starch/lignin) to facilitate 
the process and improve the strength of the product. During the pressing the temperature in the product is increased which leads to a reduction of moisture content with $1-2 \%$. The capacity for a press is normally 4-5 tonnes/h.

\subsubsection{Cooling and sieving}

After the pressing the product needs to be cooled down. The pellets leave the pelletizers then enter the pellet coolers. In this process a screening (with cyclones) is also done to eliminate a not bonded fine fraction. This component is normally recirculated to the pelletizing. Only one reported value for the PM emissions to air $\left(17 \mathrm{mg} / \mathrm{m}^{3}\right)$ from the cooling were found.

\subsubsection{Product handling with packing}

Depending on the end user, the pellets are sold in bags, big bags or as a bulk product. The bags typically contain $16 \mathrm{~kg}$ and are packed on a Europallet containing 52 bags. Big bags either contain $500 \mathrm{~kg}$ or $1000 \mathrm{~kg}$. Bulk deliveries can be on trucks or boat. For bulk deliveries some emissions during load-out may arise. One reported value, $5 \mathrm{mg} / \mathrm{m}^{3}$, were found in the study.

\subsection{Briquette production}

The briquette production process is dependent on the type of raw material that is processed and if it is a stand-alone mill or is integrated with a wood industry and/or energy production. In general the major production steps in production consist of:

- Crushing (if needed)

- Drying (if needed)

- Briquettation

- Cooling

The briquette production is in some cases an introduced process in the wood industry to use the existing dry and crushed by-products.

The technique for the crushing and drying (if needed) is similar to the pellets production.

\subsubsection{Briquette pressure}

Briquettes are produced by pressing in a pumping fashion with a piston (mechanical or hydraulic) the dried raw material through a tube with a 
nozzle. The size of the tube is $40-125 \mathrm{~mm}$, which give the diameter to the briquettes. Normally no additive is introduced during the pressing.

The capacity for a press is $50-1,200 \mathrm{~kg} / \mathrm{h}$.

\subsubsection{Cooling}

The cooling mechanism is in form of another long tube, connected to the press tube, with cooling water.

\subsubsection{Product handling}

The product is handling as a bulk product.

\subsection{Environmental aspects}

\subsubsection{Emissions to air}

The most central process in pelletizing for emissions to air is the drying.

The dryer performance and emissions are dependent on the type of dryer, size of material components (sawdust, shavings or chips and wood species) and amount of moisture in the raw material.

The heat for a pellet mill dryer is typically generated by burning wood waste from the process, pellets, or other mill residues. In Finland peat is often used for the heat production. Small amounts of fossil fuels may also be used for startup the preheating, pilot lighting or dryer temperature control. The bed dryer can also handle waste heat. When comparing emission data from biomass drying the type of drying technique and installed cleaning equipment should be considered. For example, in emission data from a flue gas dryer (drum or stream dryer) the boiler emissions are also included.

\section{PM/Dust emissions}

It is informative to note a pellet industry that produces 100.000 ton/year and uses a flue gas dryer needs a 10MW boiler. This means that they fall in the low end compared to the heat and power plants. Of economical reasons the BAT should be reasonable limited.

Common abatement installations (CAI) for reducing emissions of PM in different gas flows are cyclones, electrostatic precipitators (ESP as dry or WESP as wet), fabric filter and scrubbers (incl. in FGC).

The cyclone is the standard solution in the different positions acting alone or as a pre-cleaner for ESP, fabric filter or scrubber.

In the drying of the raw material there will be a release of condensable components which can be sticky, tarry and flammable. Consequently the different gas streams from the various processes will require different treatment options. In the dryer process an ESP can with advantage 
be in the form of a wet ESP (WESP) to eliminate this problem, fabric filter is not to recommend.

The main source of PM is the dryer, when the type is drum or stream, and the CAI can be (multi-)cyclone alone or with a WESP or a scrubber.

For a steam dryer the PM is zero and for a bed it's limited (it acts as a filter itself when the airflow is from top to bottom).

In the crushing ahead of the dryer it's typically on wet material with a larger size distribution so the hammer mill can have a cyclone to handle the low level of PM.

In the processes after the dryer with the grinding, pelletizing and cooling/sieving the material is dry and the emission levels in the active air streams are on a secondary level. Here fabric filters can be installed after (multi-)cyclones. In the transportation of the material in this region and in the packing area consideration has to be made to have it as dust free as possible (enclosed) and arrange for necessary ventilation. Fire protection has to be included (explosion risk).

In Table 7 the common dust reducing equipment and their efficiency are listed.

Table 7. Common dust reducing equipments and their efficiency

\begin{tabular}{llll}
\hline Abatement & & Efficiency at diff. part. size [\%] & Applicable in \\
Equipment & $\mathbf{1}$ micron & $\mathbf{0 , 1}$ micron & wet environm. \\
\hline Multi-Cyclone & 40 & 3 & Yes \\
ESP & 98 & 95 & as WESP \\
Fabric filter & 99 & 95 & No \\
Scrubber & 80 & 15 & Yes \\
\hline
\end{tabular}

In Table 8 some emission data from the drying is shown. A bed dryer for example can easily have lower PM emissions than a flue gas dryer of drum or stream type, were the boiler emissions are included.

Table 8. Emissions of PM to air from raw material drying

\begin{tabular}{lll}
\hline Producer & Type of dryer & PM mg/m3 \\
\hline 1. SCA Bionorr & Flue gas dryer & 120 \\
5. Stora Enso Timber & Bed dryer & 15 \\
6. Neova & Drum dryer & 230 \\
\hline
\end{tabular}

In Table 9 some emission data from the grinding is shown.

Table 9. Emissions to air for PM from grinding

\begin{tabular}{ll}
\hline Source & $\mathrm{PM} \mathrm{mg} / \mathrm{m}^{3}$ \\
\hline 1. SCA Bionorr & 5 \\
5. Stora Enso Timber & 100 \\
\hline
\end{tabular}

Only one reported value for the PM emissions to air $\left(17 \mathrm{mg} / \mathrm{m}^{3}\right)$ from the cooling were found. For bulk deliveries some emissions during loadout may arise. One reported value, $5 \mathrm{mg} / \mathrm{m}^{3}$, were found in the study. 
For the PM as fugitive emissions in the storage area as windblown dust, storage piles sizes, localizations, wind break and so on has to be concerned.

\section{VOC (Volatile Organic Compounds)}

During the drying not only PM is emitted but also volatile organic compounds (VOC). The temperature/vapor pressure specific surface (great in small wood parts) and the strength of the bonding to the biomaterial influence on the VOC emissions. It is important to note that the share of the different compounds varies and there bonding. The release of VOC starts from the living forest at a low level. In general the higher the temperature the higher the evaporation of VOC will be. ${ }^{42}$ When heating harvested biomaterial, as in a dryer, the emission starts to increase drastically at around $175^{\circ} \mathrm{C}$ to reach emission level of $120 \mathrm{~g} / \mathrm{kg}$ at $350^{\circ} \mathrm{C}$ (pine bark).

With drying with flue gas the risk of odor is also a fact. If there is condensation (FGC) the amount of VOC in the gas is reduced but a part will still go ahead in the gas in concentrated form as VOC drops and create odor disturbances.

At storages of produced pellet there will be a release of VOC and CO (carbon monoxide) at a low level but if the air-change is low the concentration will go high. ${ }^{43}$ Pellet volume, temperature and air-change have to be considered. (For some of the compounds there are for Sweden occupational exposure limits, like CO 35 ppm for 8 hours exposure and 600 $\mathrm{mg} / \mathrm{m}^{3}$ for Aceton).

CAI for reducing VOC emissions (in air) is the cyclone and wet equipment as WESP and scrubbers. There are methods for reducing emissions which, however, are not at present used in Scandinavia. One is the RTO (regenerative thermal oxidizer) where combustion of the VOC creates a heat to a ceramic medium that support the combustion.

Information on VOC emissions versus temperature in pellet dryers is limited. Information for pine bark is shown in Figure 22. This pine bark data, although illustrative of the effect of temperature on VOC, may not be representative of pellet dryers, which use mainly white wood. The figure does illustrate, that as the temperature rises from $175^{\circ} \mathrm{C}$ to $275^{\circ} \mathrm{C}$, VOC emissions increase from less than $1 \mathrm{~kg} /$ ton of wood to $\sim 40 \mathrm{~kg} / \mathrm{ton}$. Above about $275^{\circ} \mathrm{C}$, VOC emissions increase rapidly (exponentially) until all of the VOCs are released. ${ }^{44}$

\footnotetext{
42 Svedberg U.

43 Svedberg U.

${ }^{44}$ HUT 2003, Spets, Jukka-Pekka and Ahtila, Pekka: Reduction of Organic Emissions by Using Multistage

Drying System for Wood based Biomasses.
} 
Figure 22. Pine Bark VOC Emissions as a Function of Temperature

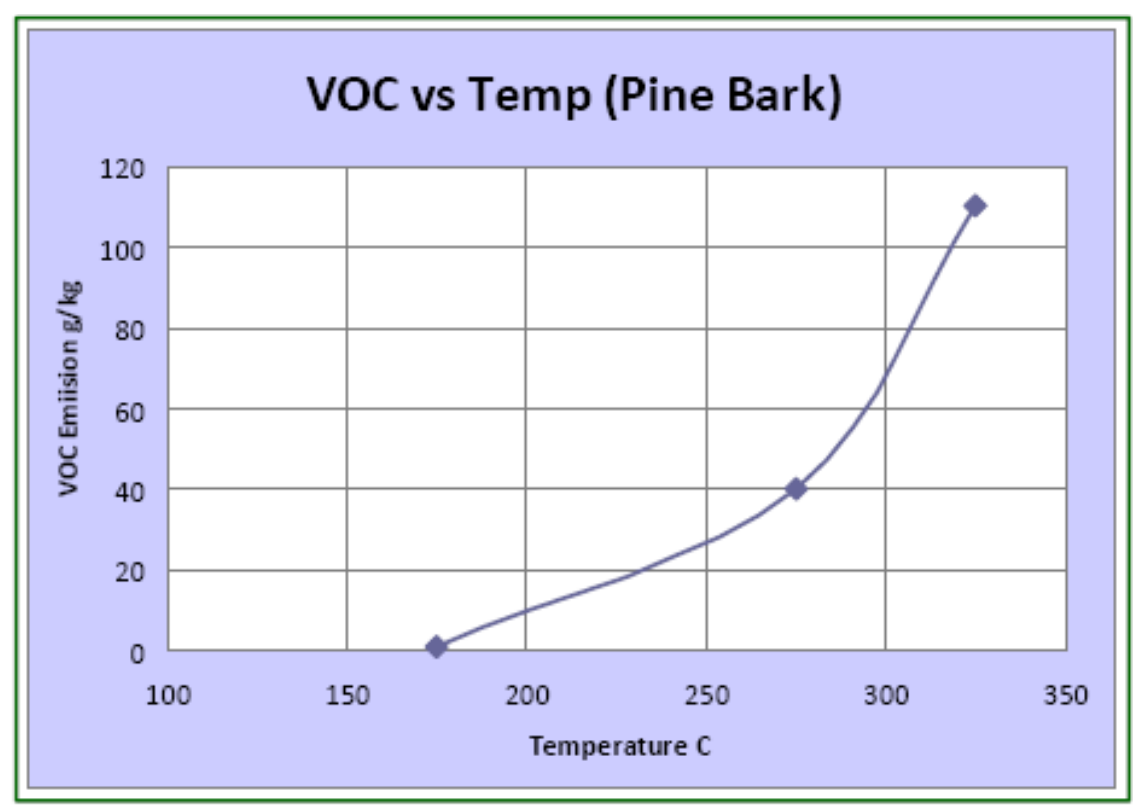

\subsubsection{Emissions to water}

The main source for emissions to water from pellets production is when there is condensation of the flue gas or dirty steam from the raw material drying process.

Condensating the biomass drying air will cause quite significant waste water load. Laboratory tests for the condensates were performed using fresh forest chips, stored forest chips, sawdust and fresh and stored bark that were dried under 150 and $180^{\circ} \mathrm{C}$ drying temperatures. Test results showed that TOC released as condensates were between $0.02-0.2$ weight- $\%$ of dry material $(140-1,800 \mathrm{mg} / \mathrm{l})$ and COD $0.1-0.8$ weight-\% of dry material $(500-2,700 \mathrm{mg} / \mathrm{l})$. The quality of the condensates depends on the raw material and its storing time. Drying stored green forest chips and pine bark caused greater organic load in condensates than fresh materials. COD in condensates of stored pine bark was $0.8 \mathrm{w}-\%$ of the dry material, for the stored forest chips COD in condensates was $0.3 \mathrm{w}-\%$ of the dry material. Fresh bark material caused more organic load than fresh forest chips. Main compounds in condensates of stored pine bark were acetic acid, ethanol and methanol. Condensates of fresh forest chips consisted of acetic acid and formic acid. Condensates of fresh materials consisted more alcohols and less acids compared to condensates of stored materials. ${ }^{45}$ 
In the other laboratory tests performed under lower temperature 100$120^{\circ} \mathrm{C}$ using fresh and stored forest chips and sawdust released TOC in condensates were between $0.01-0.09 \mathrm{w}-\%$ of dry material. The quality of the condensate depends on the raw material. When fresh green forest chips were dried the condensate consisted methanol and ethanol, these alcohols covered $40 \%$ of total TOC. Condensates of other materials consisted only methanol of alcohols. ${ }^{46}$

CAI for reducing emissions in case of condensation to water is various kinds of condensate treatment such as lamella separator and sand filter, with or without flocculation. Treatments for the condensate also used are infiltration and sludge/oil separator. With a subsequent municipal sewage system the plant solution can be limited.

In Table 10 some emission data is shown. In the case for Neova there is a water KUVO filter ahead of the FGC. The water volume is the total sum.

Table 10. Emissions to water

\begin{tabular}{|c|c|c|c|c|}
\hline Source & $Q, m 3 / y r$ & $\mathrm{Q}, \mathrm{m} 3 /$ tonne & SS mg/l & COD mg/l \\
\hline 1. SCA Bionorr (FGC) & 66,000 & 0.4 & 70 & 30 \\
\hline 2. HMAB (SreamC) & 120,000 & 0.9 & 15 & 14 \\
\hline 3. Derome Bioenergi (FGC) & & & 10 & - \\
\hline 4. Rindi Västerdala (FGC) & 50,000 & 1.1 & 10 & 11 \\
\hline 6. Neova (FGC+KUVO) & 7,000 & 0,006 & 560 & 4 \\
\hline
\end{tabular}

\subsubsection{Noise emissions}

If crushing and shipping biomass is a case at the plant they are the most significant noise sources, noise emissions in section 4.4 is also applicable for pellet production. Other main sources are the grinding, drying and pressing. The wheel loaders and trucks used for biomass loading and transportation do also create noise emissions. If the dryer is stand alone outdoors (e.g. drum dryer) the rotation mechanism with bearings can be constructed for low noise. Equipment with high airspeed (e.g. cyclones) can have exhaust silencer. Transportation with heavy machines at the plant can be scheduled.

In the Table 11 some typical limit values for noise at the nearest residential is shown.

${ }^{46}$ Fagernäs et al. 2002. 
Table 11. Noise emissions (dB(A)), limit values

\begin{tabular}{|c|c|c|c|}
\hline Source & Day, 07-18 & Evening, 18-22, & Night, 22-07 \\
\hline 1. SCA Bionorr & 50 & 45 & 40 \\
\hline 2. $\mathrm{HMAB}$ & 50 & 45 & No production allowed \\
\hline 3. Derome Bioenergi & 50 (weekdays 07-18) & $\begin{array}{l}45 \text { (evenings, } 18-22 \text { and sat- } \\
\text { sun } 07-18 \text { ) }\end{array}$ & 40 \\
\hline 4. Rindi Västerdala & 50 & 45 & 40 \\
\hline 5. Stora Enso Timber & 50 & 45 & 40 \\
\hline 6. Neova & 50 (weekdays 07-18) & $\begin{array}{l}45 \text { (evenings, } 18-22 \text { and sat- } \\
\text { sun } 07-18 \text { ) }\end{array}$ & 40 \\
\hline
\end{tabular}

Sound pressure levels from different noise sources outdoors have been measured in a plant for pellet production. In Table 12 some figures are given.

Table 12. Noise emissions ( $\mathrm{dB}(\mathrm{A}))$, measured values

\begin{tabular}{lrr} 
Source & Distance $(\mathbf{m})$ & Sound pressure level (dB(A)) \\
\hline Wheel loader & 10 & 76,4 \\
Small tractor & 10 & 76,2 \\
Unloading wood chips with truck & 10 & 69,8 \\
Cyclone after dryer & 1 & 78,9 \\
Cyclone after grinder & 1 & 90 \\
Pellet feeder for silo 1 & 1 & 80,3 \\
Pellet feeder for silo 2 & 1 & 90,4 \\
\hline
\end{tabular}





\section{Best available techniques (BAT)}

This report deals with best available techniques of producing and processing solid biomass. The main process steps and their main environmental effects are as:

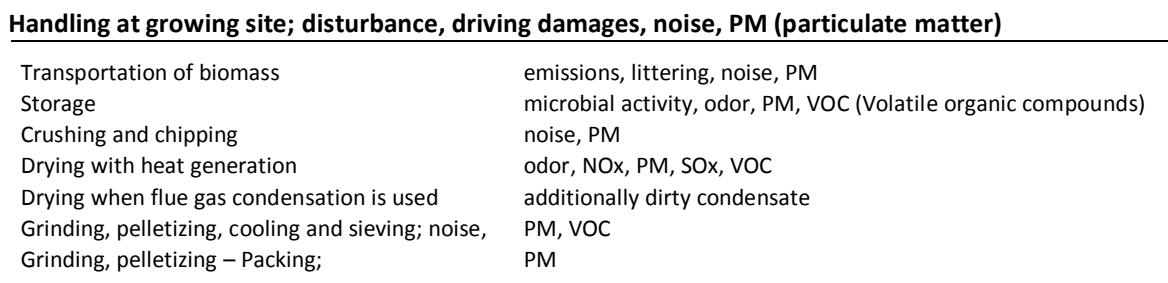

\subsection{Harvesting, natural drying and other processes at growing site}

Most of forest fuel is in practice harvested similar to industrial wood and the environmental impacts to the forests are similar to the impacts of the traditional industrial wood harvesting, which are in general covered by the forestry law.

After harvesting the main methods for production of biomass chips are chipping or crushing at the road side, at a logistics terminal, or at the point of use. To a lesser extent chipping at the harvesting site occurs. Centralizing the chipping to the point of use or in a terminal enables large annual production volumes to be produced more economically due to the high utilization rate of the machines. Because of high investment costs chipping and crushing at the point of use is only economically justifiable for large power plants. In order to limit the environmental effects of crushing and chipping outdoors the location should be selected carefully to minimize the disturbance to the surrounding area. National legislation and local requirements, particularly for noise reduction, should be complied with and these can prohibit outdoor crushing and chipping close to populated areas or other sensitive areas. Operational times for noisy activities can be also limited (by excluding nights, evenings, weekends, and public holidays) in order to limit noise exposure. Nationally/locally applicable noise limit values for noise levels (such as $50 \mathrm{~dB}(\mathrm{~A}$ ) during daytime, $45 \mathrm{~dB}(\mathrm{~A})$ during evening, $40 \mathrm{~dB}(\mathrm{~A})$ during nighttime near residential areas, and limit values can be $5 \mathrm{~dB}(\mathrm{~A})$ lower near recre- 
ational areas) should be fulfilled. Nationally/locally used administrative practices (permits/notifications/other) should be applied to determine whether the activity is allowed in a specific site. This applies also for crushing and chipping at terminals and at the point of use (Chapter 6.3) and pellet production (Chapter 6.4).

\section{BAT at growing site:}

- In order to reduce nutrient loss logging residues should be left to dry at the harvesting point in the logging area until the needles have fallen off.

- At areas with strong recreational activities, i.e. near population centers, outdoor recreation centers, protected areas and recreational settlements, harvesting must be restricted to low recreation periods.

- Noise effects should be decreased by minimizing and concentrating the activities at the growing site. Whenever possible, the activities at the growing site should be localized so that as little as possible disturbance is caused for surrounding inhabitants. This is also valid for terminals and activities at the point of use.

- To reduce microbial activity in biomass; plan the biomass storage to avoid odor and a reduction in quality. This applies also to biomass storage at terminals and point of use.

\subsection{Transportation}

Environmental aspects concerning biomass transportation are mainly related to transport efficiency and dusting/littering during transport.

\section{BAT during transportation, loading and unloading:}

- Loading and unloading of dusty biomass fuels should be organized in covered areas to avoid dust emissions.

- Dusty biomass fuels (e.g. pellets, dry saw dust, cutter shavings and wood powders) transportation should be in closed or air tight vessels, for example in tank trucks or closed or covered containers.

- Bark and crushed logging residues should be transported in covered wagons or containers in order to avoid littering.

- During transport via waterways, crushed and chipped biomass should be kept undercover, i.e. in the ship's hold.

- When straw and reed canary grass should be transported longer distances, the use of square bales is preferred to round bales in order to improve transportation efficiency. 


\subsection{Handling and storage at terminals and at the point of use}

Different biomass fuels have different properties from each other and thus the technology and processes used for handling biomass must be selected to suit the biomass properties in question. The most important properties to consider when selecting the technology and processes to use include: flowability; bulk density; moisture content; chemical content; particle size and the need for further processing; and the presence of impurities like sand, stones and metal. The health and safety issues associated with the handling of biomass must also be considered carefully.

\section{BAT for handling technology and processes at terminals and at the point of use:}

- Processing equipment should be designed for dust encapsulation and to prevent the build-up of dust on structures and surfaces.

- Noisy operations which take place on frequent intervals (daily, weekly) like crushing and chipping should preferably be located indoors. Less frequent activities (biannual, monthly) can be performed outdoors when local conditions allow this. Issues to be considered are particularly noise and PM.

- Storage periods for crushed and chipped wet biomass should be minimized to minimize odor and reduction in quality.

- Stockpiles for crushed and chipped wet biomass should be shaped and compacted to minimize fire risk, odor, reduction in quality and dusting.

- Outdoor activities should be localized with safety distances to populated areas and other areas of concern (such as schools and hospitals). By securing a protecting distance between plant and populated areas a number of environmental impacts can be minimized (such as noise, odor and PM). Recommended distance between outdoor handling and populated areas is 400 meters.

\section{BAT for control of emissions to air:}

- Handling of crushed and dusty material and production operations should be located indoors when possible.

- Conveyors for crushed and dusty materials should be enclosed, or designed to minimize or capture dust emissions.

- Fine-grained material should be transported only in enclosed conveyors.

- Dust should be removed from exhaust air before the outlet by using fabric filters or other applicable techniques. BAT for particle emission is $<20-50 \mathrm{mg} / \mathrm{Nm}^{3}$ particulates, where the lower end refers to use of fabric filters and the upper end refers to use of cyclones and other particulate removal techniques. Lower end refers also for all new 
plants. Emissions of exhaust air should be monitored annually for main emission sources.

- Water mist dispersion systems can be used to control dust emissions when they do not reduce the quality of the fuel or increase the risk of self-heating.

- In case biomass drying is applied same BAT applies as in the chapter 6.4.

\section{BAT for control of noise emissions:}

- Crushing and chipping operations should be located indoors where possible.

- Encapsulating or using protective covers for noise producing parts where possible.

- When crushing biomass outdoors, if residential areas or other disturbed areas are nearby and activity is not prohibited by the local authority:

a) Crusher machine should be equipped with an exhaust silencer.

b) For more frequent activity (daily, weekly) permanent noise barriers (optimizing the use of natural barriers) should be used to limit noise exposure. For less frequent activity (monthly, biannually) walls made of the biomass should be placed around the crusher for noise reduction. The design of the noise barriers (height, length and coverage) is site specific.

\section{BAT for control of emissions to water:}

- Storage areas should be asphalted or sealed with similar watertight layer to avoid leakages to soil and ground water.

- Sensitive ground water areas should be avoided as handling and storage areas.

- Solids should be removed from leachates and drainage waters.

- Leachates and drainage waters should be routed via a monitoring well and regular water quality control (pH, conductivity, SS, COD/TOC) should be applied.

- Areas with risk of oil spills during handling should be equipped with oil trap wells.

\subsection{Pellet production}

In the pellet production plant there are processes and process steps with different environmental impacts. Transport of material into, at and out of the mill creates emissions and noise. Exposed raw material at the storage area is susceptible for weather and wind which can bring material to the air and into the ground. In the central industrial processes; crushing, drying, grinding, pelletizing, cooling and packing dust and noise are critical aspects. During the different processes, especially drying, there is a release of VOC's and some cases considerable waste water emissions. 


\section{BAT for pellet production technology:}

- Noisy operations like crushing and chipping should preferably be performed indoors.

- The dryer (and combustion plant for dryer heat generation) should have high energy efficiency; have effective equipment for dust reduction and optimized drying temperature in order to minimize the release of VOC's from the material to exhaust air and water, when flue gas drying is used.

- Processing equipment should be designed for dust encapsulation and to prevent the build-up of dust on structures and surfaces.

- In order to improve and optimize energy efficiency and reduce the need for transports the pellet production plant should be localized next to and integrated when feasible with a sawmill, a heating plant or a pulp mill.

\section{BAT for control of dust and air emissions:}

- Dust emissions from crushing, belt drying, grinding, pelletizing, cooling and sieving, and packing should be limited to is $<20-50$ $\mathrm{mg} / \mathrm{Nm}^{3}$ particulates, where the lower end refers to use of fabric filters and the upper end refers to use of cyclones and other particulate removal techniques. Lower end refers also for all new plants. Emissions of exhaust air should be monitored annually for main emission sources.

- Dust emissions for flue gas drying should be below $100 \mathrm{mg} / \mathrm{Nm}^{3}$ particulates. Other fuel specific emission limits can be applied depending on the heat source (biomass, peat, natural gas, etc.) and should be determined taking into account the ratio of flue gas flow in relation to total gas flow of the dryer and national BAT conclusions or minimum emission limit values for $<50 \mathrm{MW}$ boilers. Emissions to air should be monitored annually.

- Unloading of raw materials and loading of end products as well as other activities should be organized indoors when possible in order to avoid dust releases to air.

\section{BAT for control of noise emissions:}

- Crushing and chipping operations should be located indoors where possible.

- Encapsulating or using protective covers for noise producing parts where possible.

\section{BAT for control of water emissions:}

- Storage areas should be asphalted or sealed with similar watertight layer to avoid leakages to soil and ground water.

- Drainage waters from all operation areas must be collected and discharged in a controlled way via a monitoring well. Regular water quality control (pH, conductivity, SS, COD/TOC) should be applied. 
- Drainage water must be discharged to the environment through oil trap wells from areas where there are risks of oil spill.

- If condensate is generated in raw material drying, waste water treatment/pretreatment is often needed. Specific requirements depend on waste water quality and local conditions. Available techniques for waste water treatment are:

a) pH-regulation, lamella separator, sand filter and chemical flocculation.

b) Regular water quality control (pH, conductivity, SS, COD/TOC, other compounds based on site specific issues) should be applied. 


\section{References}

Anon 2003. Environmental permit SCA Bionorr, Härnösand.

Pellet production plant (In Swedish).

Anon 2004, Environmental permit 73 YLO/LOS-2003-Y-1242-111/2.9.2004 of a production plant pellet handling and combustion. Suomen Megawatti Oy. SouthWest Regional Environmental Centre, Turku, Finland, 2004. (In Finnish).

Anon 2006. Environmental permit Neova, Vaggeryd. Pellet production plant (In Swedish).

Anon 2006. Environmental permit application Derome Bioenergi, Veddinge Rindi Västerdala, Vansbro. Pellet production plant (In Swedish).

Anon 2007. Environmental permit application Stora Enso Timber, Gruvön. Pellet production plant (In Swedish).

Anon 2008, Environmental permit 45/08/2/ISY-2008-Y-31 for a pilot plant of biomass drying and gasification. Stora Enso Oy and NSE Biofuels Oy. Eastern Finland Environmental Permit Agency, Kuopio, Finland, 2008 (In Finnish).

Anon 2008, NT Method, Guidelines for storing and handling of solid biofuels, NT Envir 010, Approved 2008-10, Nordic Innovation Centre.

Anon 2010. Environmental permit 29/2010/1/ESAVI/39/04.08/2010 for a gasification plant of biomass and peat. South Finland Regional State Administrative Agency, Helsinki, Finland, 2010.

Anon 2010. Environmental yearly reports HMAB, Sveg. Pellet production plant (In Swedish).

Beauchemin P, Tampier M. Emissions and Air Pollution Controls for the Biomass Pellet Manufacturing Industry. Envirochem Services Inc., North Vancover. 2010.

Energy from field energy crops - a handbook for energy producers.

Fagernäs, F., Impola, R., Rautiainen, R. Ajanko, S. Puupolttoaineiden kemialliset muutokset varastoinnissa ja kuivauksessa -PUUT 29. VTT. 2002.

Fagernäs, F., McKeough, P. Puupolttoaineiden esikäsittelyn kemialliset vaikutukset PUUT 37. VTT. 2004

Hagberg L., Särnholm E., Gode J., Ekvall T., Rydberg T.; LCA calculations on Swedish wood pellet production chains-according to the Renewable Energy Directive (RED). IVL report B1873. 2009.

Hakkila, P. Puuenergian teknologiaohjelma 1999-2003. Metsähakkeen tuotantoteknologia. Loppuraportti. Tekes. Teknologiaohjelmaraportti 5. 2004.

HUT 2003, Spets, Jukka-Pekka and Ahtila, Pekka: Reduction of Organic Emissions by Using Multistage Drying System for Wood based Biomasses. Helsinki University of Technology, 2003.

Håkansson, P. Toxicitet i lakvatten från biobränslen och dess orsaker. Göteborg universitet. 2005.

Kallio, M. Leinonen, A. Production technology of forest chips in Finland. VTT. 2005.

Kuusinen, M. \& Ilvesniemi, H. (toim), 2008. Energiapuun korjuun ympäristövaikutukset. Tapion ja Metlan julkaisuja.

Lauhanen, R., Laurila, L. Bioenergian tuotannon haasteet ja tutkimustarpeet. METLA. 2007.

Naturvårdsverket, Branschfakta, Förbränningsanläggning för energiproduktion inklusive rökgaskondensering (utom avfallsförbränning), utgåva 2, mars 2005. 
Nilsson B. Diploma work, Pre-treatment of Biomass from Forest - Efficiency and costs of different pre-treatment systems of logging residuals outtake, Växjö University, 2007 (Swedish).

Ruhanen, A. Kristiinan voimalaitosalue meluselvitys. Ramboll. 2011.

Roland Wimmerstedt, Björn Linde; "Analys av det tekniska och ekonomiska läget för torkning av biobränslen"; Värmeforsk rapport nr. 646.

SOU (2007:36) Bioenergy from the agriculture - a growing resource, (Swedish).

Sander B. \& Skott T. Bioenergy for electricity and heat - experiences from biomassfired CHP plants in Denmark, Dong Energy, 2007.

Svedberg U., Förekomst och bildning av flyktiga ämnen vid tillverkning och förvaring av träpellets. Yrkes- och miljömedicinska kliniken, Sundsvalls Sjukhus, 2003.

Thorsén Å., Björnheden R., Eliasson L., Efficient forest fuel supply systems - Composite report from a four year R\&D program 2007-2010, Skogforsk.

\section{Internet references}

Energy Statistics 2010, Danish Energy Agency, http://www.ens.dk/en-US/Info/ FactsAndFigures/Energy_statistics_and_indicators/Annual\%20Statistics/Sider/ Forside.aspx (April 2012).

National Energy Authority of Iceland, 2010, http://www.nea.is/the-national-energyauthority/energy-statistics/primary-energy/sources-of-energy/ (December 2011)

Skógarorka, http:/www.skogarorka.is/(December 2011).

Statistics Finland, 2010, http://www.stat.fi/til/ene_en.html (April 2012).

Statistical Yearbook of Forestry 2011, Metla, http://www.metla.fi/julkaisut/ metsatilastollinenvsk/index-en.htm (April 2011)

Statistics Norway, 2010 http://www.ssb.no/english/subjects/01/03/10/ energiregn_en/ (December 2011)

Statistics Sweden and Swedish energy agency, 2010 http://energimyndigheten.se/ en/Facts-and-figures1/Publications/ (April 2011)

The European Committee for Standardization (CEN) http://www.cen.eu/cen/ Sectors/TechnicalCommitteesWorkshops/CENTechnicalCommittees/Pages/ Standards.aspx?param=19930\&title=Solid\%20biofuels (December 2011)

The SolidStandards project, European Commission http://www.solidstandards.eu/ (April 2012) 


\section{Sammanfattning}

Efterfrågan av fast biomassa för energiproduktion har ökat kraftigt under de senaste decennierna och det finns inga tecken på minskning varken i de nordiska länderna eller i Europa. När EU presenterade The Climate Change Aktion Plan för att reducera behovet av fossila bränslen var biomassa en uppenbar kandidat till att ta en större del i den framtida energisammansättningen. Efter att ha uppfattats som en form av sekundär produkt från den lokala skogsindustrin, som även i vissa fall har varit svår att bli av med, är fast biomassa idag lönsamma sidoprodukter som kan transporteras lång väg. Energiskog samt odlad biomassa är produkter som har utvecklats just för energiändamål och trädtoppar, grenar och stubbar är nu också värda att insamla från skogen för att utnyttja som bränsle.

Den ökade andelen fast biomassa av varierande typ som nu ingår i energiproduktionen har medfört nya störningar i den lokala miljön. Nedskräpning, damning och buller kan förekomma på ställen där biomassa behandlas. Specifika processer i produktionskedjan såsom tillverkning av pellets, torkning av biomassa samt storskalig förvaring av biomassa bidrar också med utsläpp till luft, vatten och mark. Miljöaspekterna i denna studie fokuseras huvudsakligen just på dessa lokala utsläpp och konsekvenser.

Den fasta biomassa som ingår i denna studie har fördelats i tre delar: skogsbränsle, odlad biomassa med jordbruksrester och processad fast biomassa, se Figur 1. Torv har avsiktligt lämnats utanför denna studie.

Figur 23. Schematisk beskrivning av biomassor som ingår i denna studie

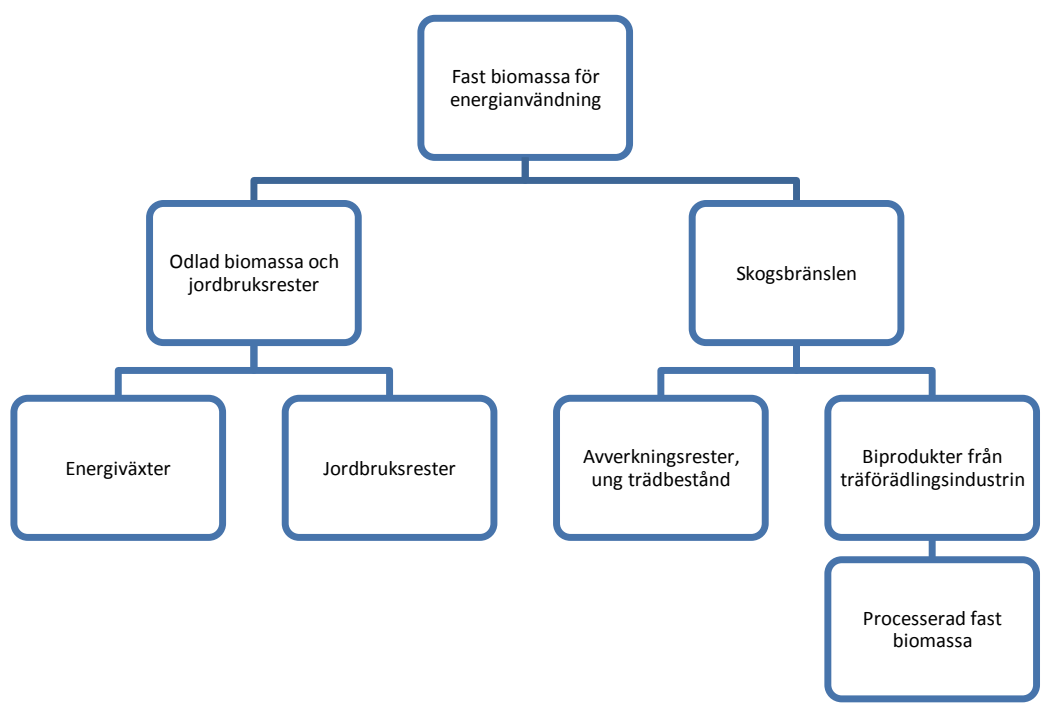


Statistisk information över andelen fast biomassa som användes för energiändamål i de nordiska länderna under år 2010 visar följande; Danmark hade cirka 28 TWh biomassa i sin totala energiförsörjning, Finland 87 TWh, Norge 15 TWh och Sverige 127 TWh. På Island var biomassans andel obetydlig.

Den drivande faktorn för skogs avverkning är normalt utnyttjandet inom sågverks samt massa- och pappersindustrin. De delar av träden som rejekteras av dessa industrier används vanligen för energiändamål. Ett exempel är avverkningsrester; där ingår till exempel trätoppar, grenar, bark och unga träd. För att undvika brist på näringsämnen i skogen bör den resulterande askan vid förbränningen av dessa avverkningsrester returneras till skogen.

Efter avverkning är det vanliga metoden att producera biomassan som trädflis flishuggning antingen vid skogsvägar nära avverkningsplatsen, vid logistikterminaler eller vid användningsplatsen (t. ex värmeverk).

Kompaktering av torkade biomassa till pellets eller briketter är ett sätt att göra biomassan mer attraktiv för olika slutanvändare. Den lägre fukthalten i pellets och briketter resulterar i ett högre energiinnehåll och en ökad energidensitet som gör dessa produkter mer lämpliga för transporter jämfört med rå biomassa.

Biomassa för energiändamål kan också erhållas från jordbruket och de mest signifikanta källorna är odlad biomassa (energiväxter) och jordbruksrester (t.ex. halm).

Huvudsakliga behandlingsprocesser samt deras miljökonsekvenser är:

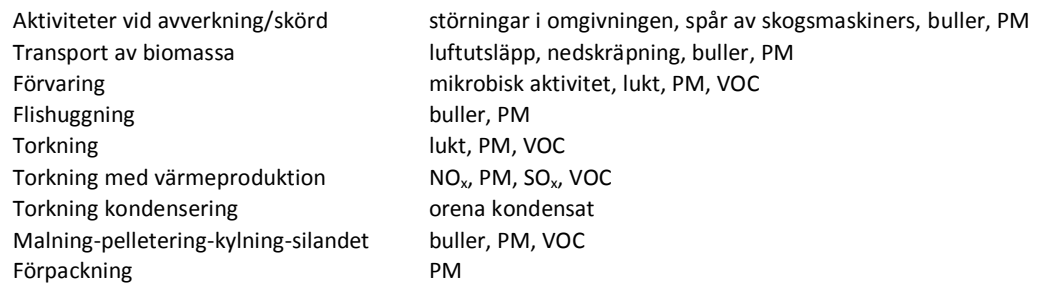

PM Particulate matter; partkulärt material - Utsläpp av damm

VOC Volatile organic compounds emissions; avdunstande organiskt material 
Nordisk Ministerråd

Ved Stranden 18

DK-1061 København K

www.norden.org

\section{Best Available Techniques (BAT) in solid biomass fuel processing, handling, storage and production of pellets from biomass}

With the increasing use of biomass fuels the varieties of sources for biomass have expanded to almost all possible combustible matter with biological origin. The increasing scale in solid biomass fuel production and utilization at the combustion plants of the wide variety of biomass fuels have contributed to littering, dust, odor and noise emissions of the production chain.

The report aims to provide information for operators, environmental consultants and competent environmental authorities on what is considered BAT, as defined in the IPPC directive (2008/1/EC), in biomass processing and handling as well as the production of pellets from biomass.

The project gives a brief description of commonly used solid biomass fuels and the processes, handling and storage of these biomasses in the Nordic countries covering processes from production site to the point of use. Environmental emissions, sources of waste and other relevant environmental aspects from commonly used processes, included raw material and energy use, chemical use and emissions to soil are also included in the report.

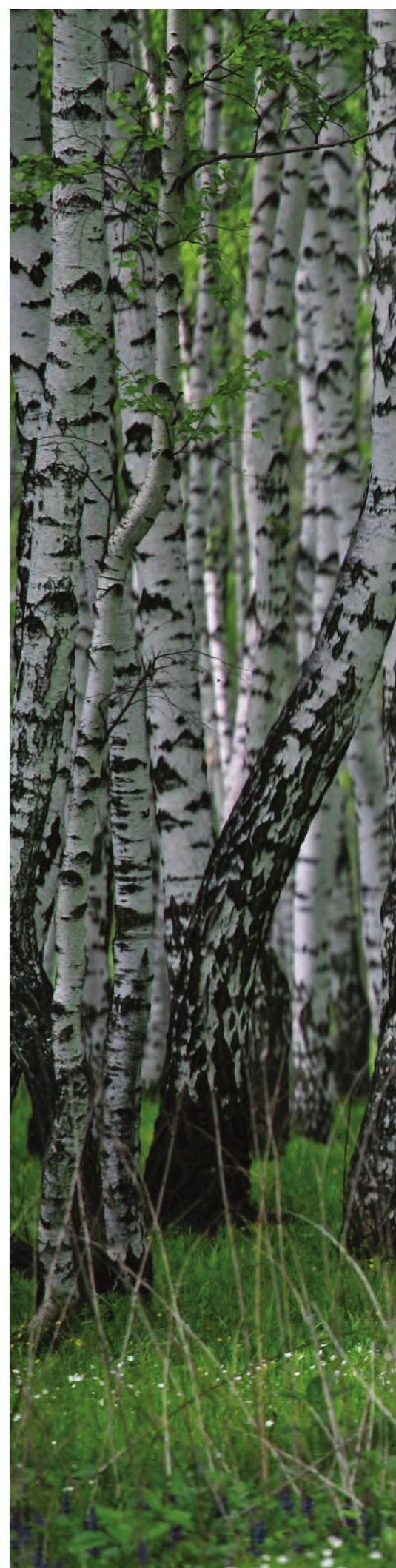

